\title{
Arctic Amplification of Anthropogenic Forcing: A Vector Autoregressive Analysis
}

\author{
Philippe Goulet Coulombe ${ }^{\mathrm{a}}$ AND MAXimilian GÖBel ${ }^{\mathrm{b}}$ \\ ${ }^{\text {a } U n i v e r s i t y ~ o f ~ P e n n s y l v a n i a, ~ D e p a r t m e n t ~ o f ~ E c o n o m i c s, ~ P h i l a d e l p h i a, ~ P e n n s y l v a n i a ~}$ \\ ${ }^{\mathrm{b}}$ Lisbon School of Economics and Management (ISEG), Universidade de Lisboa, Lisbon, Portugal
}

(Manuscript received 8 May 2020, in final form 9 January 2021)

\begin{abstract}
On 15 September 2020, Arctic sea ice extent (SIE) ranked second-to-lowest in history and keeps trending downward. The understanding of how feedback loops amplify the effects of external $\mathrm{CO}_{2}$ forcing is still limited. We propose the VARCTIC model, which is a vector autoregression (VAR) designed to capture and extrapolate Arctic feedback loops. VARs are dynamic simultaneous systems of equations, routinely estimated to predict and understand the interactions of multiple macroeconomic time series. The VARCTIC is a parsimonious compromise between full-blown climate models and purely statistical approaches that usually offer little explanation of the underlying mechanism. Our completely unconditional forecast has SIE hitting 0 in September by the 2060s. Impulse response functions reveal that anthropogenic $\mathrm{CO}_{2}$ emission shocks have an unusually durable effect on SIE - a property shared by no other shock. We find albedo- and thickness-based feedbacks to be the main amplification channels through which $\mathrm{CO}_{2}$ anomalies impact SIE in the short and medium runs. Furthermore, conditional forecast analyses reveal that the future path of SIE crucially depends on the evolution of $\mathrm{CO}_{2}$ emissions, with outcomes ranging from recovering SIE to it reaching 0 in the 2050s. Finally, albedo and thickness feedbacks are shown to play an important role in accelerating the speed at which predicted SIE is heading toward 0.
\end{abstract}

KEYWORDS: Arctic; Ice loss/growth; Ice thickness; Statistical techniques; Time series; Statistical forecasting

\section{Introduction}

With 3.74 million $\mathrm{km}^{2}$ on 15 September 2020, Arctic sea ice extent ranked second-to-lowest in history, after the record minimum in 2012. A persistent retreat of SIE may further accelerate global warming and threaten the composition of the Arctic's ecosystem (Screen and Simmonds 2010). The Coupled Model Intercomparison Project (CMIP) assembles long-run projection estimates of Arctic sea ice from many climate models. These models try to reproduce the geophysical dynamics and interrelations among various variables, influencing the evolution of global climate.

With CMIP being in its sixth phase (CMIP6), climate models now provide more realistic forecasts of the Arctic sea ice cover compared to its predecessor CMIP5 (see Stroeve et al. 2012; Notz et al. 2020). The majority of contributors to CMIP6 see the Arctic's September mean sea ice retreating below the $1 \times 10^{6} \mathrm{~km}^{2}$ mark before the year 2050. Despite following the hitherto accepted physical laws of our climate, its chaotic nature (i.e., the obscure interplay of various climate variables) imposes a major burden on climate models. Repeated initialization with differing starting conditions is intended to reduce uncertainty and biases surrounding initial parameters. The by-product is a wide range of projections of key climate variables (Notz et al. 2020). In addition to such tuning, these simulations require large amounts of input data and a coupling of various submodels (Taylor et al. 2012).

The above raises the question of whether an approach that is statistical and yet multivariate can paint a more conciliating picture. This entails estimating a statistical system that depicts the interaction of key variables describing the state of the

Corresponding author: Philippe Goulet Coulombe, gouletc@sas. upenn.edu
Arctic. In such a setup, the downward SIE path will be an implication of a complete dynamic system based on the observed climate record. We provide a formal statistical assessment of different hypotheses about the historical path of SIE and outline the implications for the future. The effects on Arctic sea ice arising from various physical processes and the uncertainty surrounding their estimation can both be quantified without resorting to using a climate model.

\section{a. Feedback loops}

Feedbacks are dynamics initially triggered by an external shock to the system. Such a disturbance can be of radiative nature or not. ${ }^{1}$ Our analysis aims at better understanding how feedback loops and their interaction with anthropogenic carbon dioxide $\left(\mathrm{CO}_{2}\right)$ forcing shape the response of key Arctic variables, and most notably, sea ice. ${ }^{2} \mathrm{CO}_{2}$ forcing is already widely suspected to be the main driver behind long-run SIE evolution (see Meier et al. 2014; Notz 2017). Feedback loops are well documented in the literature (Parkinson and Comiso 2013; Winton 2013; Stuecker et al. 2018; McGraw and Barnes 2020) and their understanding is crucial for enhancing the predictability of the Arctic's sea ice cover (Wang et al. 2016; Notz et al. 2020). Only an approach that considers the interaction of many variables in a flexible way, and thus numerous potential sources for feedback loops, has a chance to depict a reliable statistical portrait of the Arctic. CMIP6 models consider many variables, but the high variation in sea ice projections (Notz et al. 2020) suggests (among

\footnotetext{
${ }^{1}$ In contrast, internal variability, another source of climactic variation, describes fluctuations emerging from within the climate system (Kay et al. 2015).

${ }^{2}$ A detailed description of various feedbacks, which the VARCTIC is capable of modeling, can be found in Goosse et al. (2018).
} 
other things) widespread uncertainty around how strongly feedback loops may amplify external forcing. To shed more compelling statistical light on the matter, we borrow a methodology from economics.

\section{b. The VARCTIC model}

Our analysis focuses on the evolution of the long-term trajectory of SIE and the interdependent processes behind it. The modeling approach that we propose achieves a desirable balance between purely statistical and theoretical/structural approaches. In many fields, statistical approaches often have a better forecasting record than theory-based models. ${ }^{3}$ An obvious drawback is that the successful statistical model may provide little to no explanation of the underlying physical processes.

A vector autoregression (VAR) lives in a useful middle ground. It is a statistical model that yet generates forecasts by iterating a complete system of different equations in multiple endogenous variables. These interactions can be analyzed and provide an explanation for the resulting forecasts. Taking all of this into account, we propose the VAR for the Arctic (VARCTIC), a statistical approach that (i) can generate longrun forecasts, (ii) can explain them as the result of feedback loops and external forcing, and (iii) allows us to analyze how the Arctic responds to exogenous impulses/anomalies.

\section{c. Roadmap}

We first discuss the data and its transformation in section 2. We proceed with discussing the VAR model, its identification, and Bayesian estimation in section 3. Section 4 contains the empirical results, which comprise (i) a long-run forecast of SIE, (ii) impulse response functions of the VAR, (iii) an exploration of the transmission mechanism (feedback loops), and (iv) a conditional forecasting analysis. We conclude and propose directions for future research in section 5 .

\section{Data}

Our dataset comprises 18 time series, proxying the Arctic's climate system and accounting for potential feedback loops among the different constituents. The sample covers monthly observations from 1980 through 2018. We rely on standard data providers (Stroeve and Notz 2018), which are listed in Table B1 in appendix B. We combine eight variables, whose importance has been highlighted by the existing literature (Meier et al. 2014), into VARCTIC 8, our benchmark specification. Fortunately, variables can easily be added to or removed from a VAR. Bayesian shrinkage ensures that a larger model will not overfit; the latter aspect is further explained in section $3 \mathrm{e}$. Therefore, the appendix contains VARCTIC 18, which includes an additional 10 series from the reanalysis product MERRA-2 (Gelaro et al.

\footnotetext{
${ }^{3}$ When it comes to September Arctic sea ice, statistical approaches supplanted dynamical models for at least the last 3 years, as per the Sea Ice Prediction Network's Sea Ice Outlook postseason reports (Bhatt et al. 2019). Statistical models showed much less disparity than theory-based alternatives and, most importantly, consistently provided a median forecast closer to the realized value.
}

2017) as a robustness check. In summary, the two specifications considered in this paper are the following:

1) VARCTIC 8: $\mathrm{CO}_{2}$, total cloud cover (TCC), precipitation rate (PR), air temperature (AT), sea surface temperature (SST), sea ice extent (SIE), sea ice thickness (SIT), and albedo;

2) VARCTIC 18: SWGNT, SWTNT, $\mathrm{CO}_{2}$, LWGNT, TCC, TAUTOT, PR, TS, AT, SST, LWGAB, LWTUP, LWGEM, SIE, Age, SIT, EMIS, and albedo.

A comprehensive overview of all variables (including those of VARCTIC 18), their acronyms, and links to data providers can be found in the appendix in Table B1. ${ }^{4} \mathrm{We}$ want the VARCTIC to be a credible approximation of a completely endogenous system, where local processes jointly determine each other, without significant external dependencies outside of forcing. ${ }^{5}$ Thus, we restrict the spatial coverage to a regional rather than a global scale. In line with the literature (Notz and Stroeve 2016), all variables-except $\mathrm{CO}_{2}$, which is measured globally, and SST, which is measured over the Northern Hemisphere (Horvath et al. 2020) —are monthly means over all grid cells between $30^{\circ}$ and $90^{\circ} \mathrm{N}$ latitude. This region matches the spatial coverage of the sea ice index and is in the neighborhood of the lower bound of $40^{\circ} \mathrm{N}$ latitude applied in Horvath et al. (2020). ${ }^{6}$ It is a legitimate concern that averaging over too large of a region could wrongfully blend together midlatitude events with others more specific to the Arctic Circle. Fortunately, all key findings remain unchanged when restricting the gridded variables of TCC, PR, AT, and albedo to the $60^{\circ}-90^{\circ} \mathrm{N}$ domain. An interesting avenue for future research is to consider a (larger) VAR where means over various latitude ranges are included to study their interactions and relationship with SIE.

Further, we follow Oelke et al. (2003) and use AT measured at a sigma level of 0.995 (i.e., at 0.995 times each grid cell's surface-level pressure). For its part, the important choice of VARCTIC 8's variables (and additions in VARCTIC 18) will be described extensively in section $3 \mathrm{c}$.

The raw data are highly seasonal, but the feedback loops we wish to estimate and extrapolate reside in the (stochastic) trend components and short-run anomalies. Hence, we proceed to transform the data so that the resulting VARCTIC is fitted on deviations from seasonal means. For our benchmark analysis, we use a simple and transparent transformation: we deseasonalize our data by regressing a particular variable $y^{\text {raw }}$ on a set of monthly dummies. That is, for each variable we run the regression

\footnotetext{
${ }^{4}$ The primary goal was to assemble empirical data on key climate variables. To capture the most prominent feedbacks on SIE (see Meier et al. 2014), we augmented the observed series for $\mathrm{CO}_{2}$, SIE, $\mathrm{PR}$, and the assimilated PIOMAS product SIT, with data from model output. Our choice of data series is conditioned on whether they are (i) operated by well-established climate science institutions and (ii) cited in the literature.

${ }^{5}$ This is precisely what allows us to iterate the system forward (see section 3c) in order to obtain statistical forecasts based on a dynamic system.

${ }^{6}$ Previous studies have emphasized the interdependencies between weather effects in the midlatitudes and the Arctic (McGraw and Barnes 2018; Screen et al. 2015).
} 

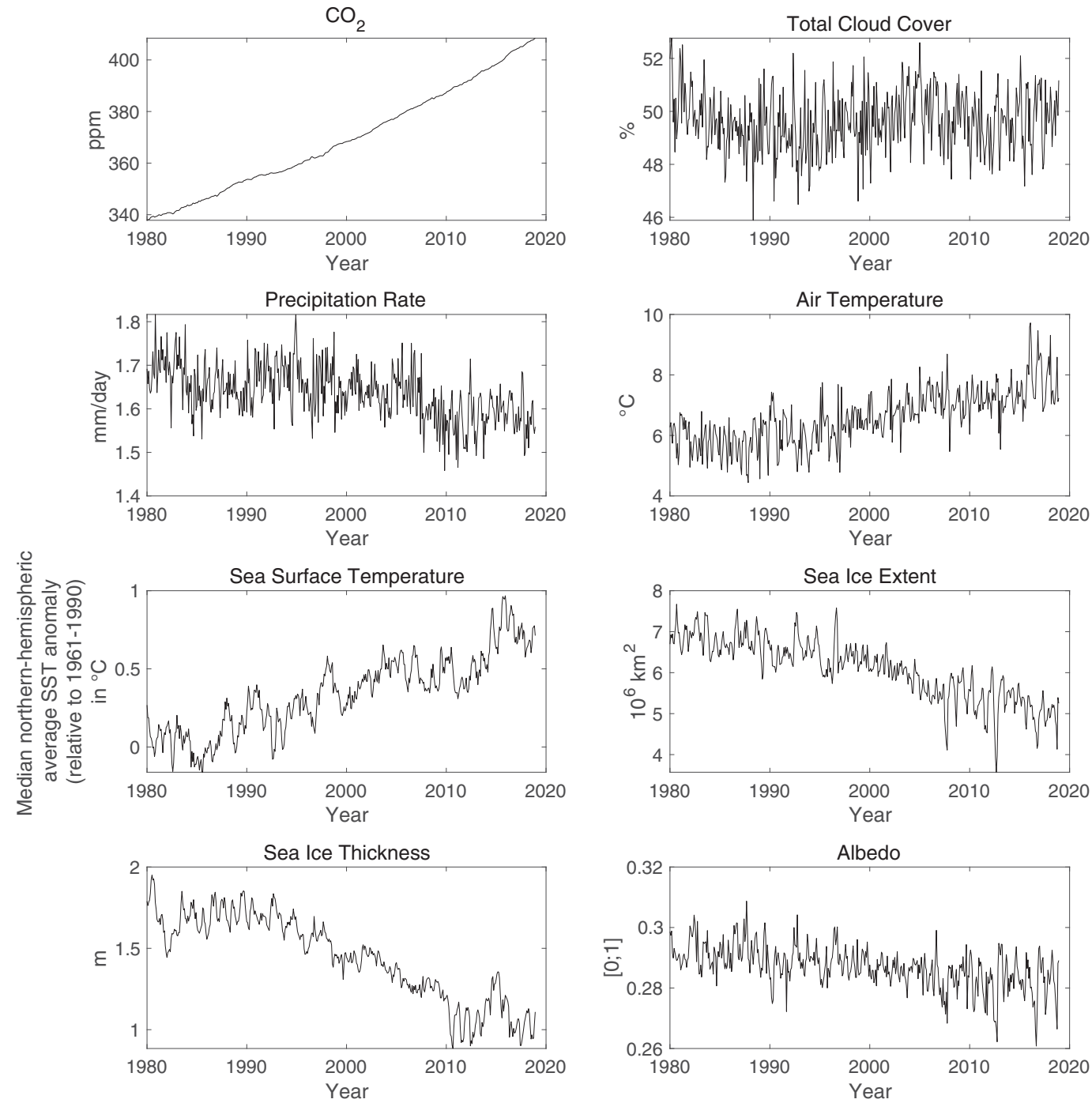

FIG. 1. Deseasonalized series for eight variables.

$$
y_{t}^{\text {raw }}=\sum_{m=1}^{12} \alpha_{m} D_{m}+\text { residual }_{t},
$$

with $\mathbf{y}_{t}$ being defined as $\mathbf{y}_{t} \equiv y_{t}^{\text {raw }}-\sum_{m=1}^{12} \hat{\alpha}_{m} D_{m}$. The term $D_{m}$ is an indicator that is 1 if date $t$ is in month $m$ and 0 otherwise. The estimates of $\alpha_{m}, \hat{\alpha}_{m}$, are obtained by ordinary least squares. This is exactly equivalent to subtracting the monthly mean (month by month) of each data series and is a more flexible approach to modeling seasonality than using Fourier series. ${ }^{7}$ Finally, we keep our filtered data $\mathbf{y}$ in levels. We do not want to

\footnotetext{
${ }^{7}$ Of course, if we were using higher-frequency data, like daily observations, then the Fourier approach would be much more parsimonious and potentially preferable (Hyndman 2010). The dummies approach to taking out seasonality only requires 12 coefficients with monthly data, but 365 with hypothetical daily data.
}

employ first differences or growth rate transformations to make the data stationary. Such an action would suppress longrun relationships, which are an important object of interest. Figure 1 shows the data after being filtered with monthly dummies. $^{8}$

\section{The VARCTIC}

In this section, we review the VAR: the model, its identification, and its Bayesian estimation. Furthermore, we discuss the construction of the long-run forecasts and impulse response functions as tools to understand the VARCTIC's results.

\footnotetext{
${ }^{8}$ Note that $\mathrm{CO}_{2}$ is available without seasonality from the data provider (NOAA-ESRL) and thus was not passed through the dummies filter.
} 


\section{a. Vector autoregressions and climate}

Vector autoregressions are dynamic simultaneous systems of equations. They can characterize a linear dynamic system in discrete time. The methodology was introduced to macroeconomics by Sims (1980) and is now so widely used that it almost became a field of its own (Kilian and Lütkepohl 2017). It is a multivariate model in the sense that $\mathbf{y}_{t}$ in

$$
\mathbf{A} \mathbf{y}_{t}=\boldsymbol{\Psi}_{0}+\sum_{p=1}^{P} \boldsymbol{\Psi}_{p} \mathbf{y}_{t-p}+\boldsymbol{\varepsilon}_{t}
$$

is an $M \times 1$ vector. This means that the dynamic system incorporates $M$ variables. The terms $\boldsymbol{\Psi}_{p}$ parameterizes how each of these variables is predicted by its own lags and lags of the $M-1$ remaining variables. The matrix $\mathbf{A}$ characterizes how the $M$ different variables interact contemporaneously-for example, how AT affects SIE within the same month (a time unit $t$ in our setup). Finally, the disturbances are mutually uncorrelated with mean zero:

$$
\varepsilon_{t}=\left[\varepsilon_{1, t}, \ldots, \varepsilon_{M, t}\right] \sim N\left(0, I_{M}\right) .
$$

Equation (2) is the so-called structural form of the VAR, which cannot be estimated because $\mathbf{A}$ is not identified by the data. For clarity, the elements of $\mathbf{A}$ are not plain regression coefficients, but structural model parameters. Attempting to estimate those directly via least squares would be plagued by simultaneity bias (Kilian and Lütkepohl 2017). Rather, structural VAR estimation proceeds in two steps. First, an estimable "reduced-form" VAR is fitted to the data. That is, we run

$$
\mathbf{y}_{t}=\mathbf{c}+\sum_{p=1}^{P} \boldsymbol{\Phi}_{p} \mathbf{y}_{t-p}+\mathbf{u}_{t},
$$

where $\mathbf{c}=\mathbf{A}^{-1} \Psi_{0}$ and $\boldsymbol{\Phi}_{p}=\mathbf{A}^{-1} \Psi_{p}$ are both regression coefficients. Now $\mathbf{u}_{t}$ are regression residuals

$$
\mathbf{u}_{t}=\left[u_{1, t}, \ldots, u_{M, t}\right] \sim N\left(0, \boldsymbol{\Sigma}_{u}\right),
$$

which are allowed to be cross-correlated. By construction, $\boldsymbol{\Sigma}_{u}=\mathbf{A}^{-1 /} \mathbf{A}^{-1}$. This last relationship is key to the second socalled identification step. In other words, this means that the covariance matrix of regression residuals from the first step $\left(\boldsymbol{\Sigma}_{u}\right)$ can be used as raw material to retrieve the "structural" A-the latter, as we stressed earlier, cannot be estimated directly. The process for obtaining $\mathbf{A}$ by decomposing $\boldsymbol{\Sigma}_{u}$ is addressed on its own in section $3 \mathrm{c}$.

The methodology has many advantages over simple autoregressive distributed lags (ARDL) regression, which has gained some popularity in the econometric and climate literature. For instance, in McGraw and Barnes (2018), the argument for inclusion of lags of the dependent variable can be interpreted as one for completeness of the modeled dynamic system, as guaranteed by an adequately specified VAR.

\section{b. Obtaining long-run forecasts from a VAR}

The symmetry of the VAR allows for it to generate forecasts by simply iterating the model. ${ }^{9}$ Assuming the chosen variables

\footnotetext{
${ }^{9}$ Further, forecasting does not rely on the matrix $\mathbf{A}$
}

to characterize the system completely, we can forecast its future state by iterating a particular mapping. To do so, we use a representation that exploits the fact that any $\operatorname{VAR}(P)$ (i.e., with $P$ lags) can be rewritten as a $\operatorname{VAR}(1)$, using the so-called companion matrix, ${ }^{10}$ thereby obtaining forecasts amounts to iterate

$$
\hat{\mathbf{Y}}_{t+1}=F\left(\hat{\mathbf{Y}}_{t}\right) \equiv \boldsymbol{\kappa}+\boldsymbol{\Phi} \hat{\mathbf{Y}}_{t}, \quad \text { to obtain } \quad \hat{\mathbf{Y}}_{t+h}=F^{h}\left(\mathbf{Y}_{t}\right)
$$

where $F$ is the 1-month-ahead forecasting function, while $\boldsymbol{\kappa}$ and $\boldsymbol{\Phi}$ are the companion-form analogs of $\mathbf{c}$ and $\boldsymbol{\Phi}_{p}$ in (3). This equation provides forecasts of all variables, $h$ periods from time $t$. An obvious $t$ to consider is $T$, the end of the sample. The fact that we can obtain predictions by simply iterating the system is of interest to generate scenarios for the Arctic. First, the prediction will rely on an explainable mechanismpotentially mixing external forcing and internal feedback loops-rather than a purely statistical relationship. Second, our forecast does not rely in any way on external data or forecasts made exogenously by some other entity, which would rely on assumptions implicitly incompatible with ours. Nevertheless, in some cases, it may be desirable to mix some external forecasts/scenarios of certain variables (like $\mathrm{CO}_{2}$ ) that may be less successfully characterized by the VAR. We consider this in section $4 d$.

\section{c. Identification}

While conditional and unconditional forecasting are important byproducts of the VARCTIC, another objective of our analysis is to understand from a statistical standpoint the underlying process driving interactions between key Arctic variables. For instance, by forecasting SIE conditional on various emission scenarios, we will later show that anthropogenic $\mathrm{CO}_{2}$ forcing is the main driving force behind the long-run forecast-cutting emissions dramatically would prevent SIE from going to $0 .{ }^{11}$ This important result rests solely on the reduced-form VAR. However, to uncover and interpret the mechanism that amplifies $\mathrm{CO}_{2}$ 's effect on SIE, we need an identification scheme for instantaneous relationships. In time series analysis, the identification problem originates from simultaneity in the data. Multivariate time series data can tell us whether $\mathbf{X}_{t-1} \rightarrow \mathbf{Y}_{t}$ or $\mathbf{Y}_{t-1} \rightarrow \mathbf{X}_{t}$ is more plausible. This is predictive causality in the sense of Granger (1969). However, the data by themselves cannot distinguish $\mathbf{X}_{t} \rightarrow \mathbf{Y}_{t}$ from $\mathbf{X}_{t} \leftarrow \mathbf{Y}_{t}$. Put simply, a single correlation between $\mathbf{X}_{t}$ and $\mathbf{Y}_{t}$ can be generated by two different causal structures. Within the VAR, the problem boils down to the need for identifying $\mathbf{A}$ in Eq. (2). Yet, the data only procure us the variance-covariance matrix of the residuals $\hat{\Sigma}$. The identification problem emerges from the

\footnotetext{
${ }^{10}$ In short, any $\operatorname{VAR}(P)$ in $M$ variables can be rewritten as a VAR(1) in $M \times P$ variables, such that the theoretical analysis can be carried out with the less burdensome VAR(1) (Kilian and Lütkepohl 2017). The $\mathbf{Y}_{t}$ are stacked $\mathbf{y}_{t-p}$ for $p=1, \ldots, P$.

${ }^{11}$ In contrast, an unconditional forecast lets the VARCTIC generate internally future paths for all variables (including $\mathrm{CO}_{2}$ ) without relying on externally developed scenarios.
} 
fact that $\mathbf{A}$ is not the only matrix satisfying $\hat{\Sigma}_{u}=\mathbf{A}^{-1 /} \mathbf{A}^{-1}$. Fortunately, there exist many ways to pin down a single $\mathbf{A}$ matrix without having to delve into too much theory, which is partially responsible for the popularity of VARs among applied economists. The strategy we opt for is the traditional Choleski decomposition of $\hat{\Sigma}_{u}$. Mechanically, it provides a lowertriangular matrix $\mathbf{C}$, satisfying $\hat{\Sigma}_{u}=\mathbf{C}^{\prime} \mathbf{C}$ (where $\mathbf{C} \equiv \mathbf{A}^{-1}$ for convenience). Its purpose is to transform regressions residuals $\mathbf{u}_{t}$ [Eq. (3)] into uncorrelated structural shocks $\boldsymbol{\varepsilon}_{t}$ [Eq. (2)]. This is done by reversing the relationship $\mathbf{u}_{t}=\mathbf{C} \boldsymbol{\varepsilon}_{t}$. Uncorrelatedness is essential (as further discussed in section $3 \mathrm{~d}$ ) in studying how the VARCTIC responds to a given impulse, keeping everything else constant. Such a causal claim would be impossible when considering an impulse from correlated residuals $\mathbf{u}_{t}$, as those always comove. In other words, studying $\mathbf{u}_{t}$ assuming everything else stays constant is generally inconsistent with the data. To summarize, the Choleski decomposition is one way to transform the observed (but practically useless) $\mathbf{u}_{t}$ into the very useful (but originally unobserved) fundamental shocks $\boldsymbol{\varepsilon}_{t}$.

The assumption underlying such an approach to orthogonalization is a causal ordering of shocks. First, it is worth cataloging the relationships, noting which get restricted by the ordering choice and which do not. The dynamics (lead-lag relationships as characterized by $\boldsymbol{\Psi}$ ) of the VAR are exempted as they are already completely identified by the data themselves. Rather, the ordering restricts how variables interact together within the same month, conditional on the previous state of the system. This is done by making an explicit assumption about the composition of (reduced-form) deviations of Arctic variables from their predicted values (i.e., the anomalies). Precisely, the lower-triangular structure of (5) implies that residuals of a variable at position $i$ are only comprised of structural shocks $\varepsilon_{t}$ of variables ordered before it. To make that explicit, we report $\mathbf{u}_{t}=\mathbf{C} \boldsymbol{\varepsilon}_{t}$ in full:

$\left[\begin{array}{l}u_{t}^{\mathrm{CO}_{2}} \\ u_{t}^{\mathrm{TCC}} \\ u_{t}^{\mathrm{PR}} \\ u_{t}^{\mathrm{AT}} \\ u_{t}^{\mathrm{SST}} \\ u_{t}^{\mathrm{SIE}} \\ u_{t}^{\mathrm{SIT}} \\ u_{t}^{\mathrm{Alb}}\end{array}\right]=\left[\begin{array}{llllllll}c_{11} & 0 & 0 & 0 & 0 & 0 & 0 & 0 \\ c_{21} & c_{22} & 0 & 0 & 0 & 0 & 0 & 0 \\ c_{31} & c_{32} & c_{33} & 0 & 0 & 0 & 0 & 0 \\ c_{41} & c_{42} & c_{43} & c_{44} & 0 & 0 & 0 & 0 \\ c_{51} & c_{52} & c_{53} & c_{54} & c_{55} & 0 & 0 & 0 \\ c_{61} & c_{62} & c_{63} & c_{64} & c_{65} & c_{66} & 0 & 0 \\ c_{71} & c_{72} & c_{73} & c_{74} & c_{75} & c_{76} & c_{77} & 0 \\ c_{81} & c_{82} & c_{83} & c_{84} & c_{85} & c_{86} & c_{87} & c_{88}\end{array}\right] \times\left[\begin{array}{c}\varepsilon_{t}^{\mathrm{CO}_{2}} \\ \varepsilon_{t}^{\mathrm{TCC}} \\ \varepsilon_{t}^{\mathrm{PR}} \\ \varepsilon_{t}^{\mathrm{AT}} \\ \varepsilon_{t}^{\mathrm{SST}} \\ \varepsilon_{t}^{\mathrm{SIE}} \\ \varepsilon_{t}^{\mathrm{SIT}} \\ \varepsilon_{t}^{\mathrm{Alb}}\end{array}\right]$.

Only if variable $i$ is ordered below variable $j$ will a "fundamental" shock to $j$ affect variable $i$ contemporaneously. Otherwise, variable $i$ will experience the effect of that shock with a lag of at least 1 month (which corresponds to one time unit in the application). For example, the $\mathrm{CO}_{2}$ anomalies (meaning unpredictable by the past behavior of any of the eight variables) are assumed to be composed of structural $\mathrm{CO}_{2}$ shocks only. This implies that the effects of the other variables on $\mathrm{CO}_{2}$ take at least a month (but perhaps more) to set in. In contrast, SIE or albedo anomalies can be composed of a variety of fundamental shocks. Those restrictions are not without cost as the ordering of the variables may influence our understanding of the mechanism uncovered by the VARCTIC. This is why the ordering must be motivated based on the application at hand. ${ }^{12}$

\section{1) Motivation OF THE ORDERING}

It is well established that the melting SIE and the state of the Arctic environment are both results of exogenous (to other Arctic variables) human actions (Dai et al. 2019; Notz and Stroeve 2016). We view the Arctic system as being subject to feedback loops that may amplify the effect of exogenous shocks way beyond their original impact. However, the original stimulus is very likely to be anthropogenic, given that without the unprecedented increase in $\mathrm{CO}_{2}$ emissions and subsequent rise in global temperature, none of these mechanisms would have been so evident in effect (Amstrup et al. 2010; Melillo et al. 2014). ${ }^{13}$ Consequently, we order $\mathrm{CO}_{2}$ first. The implication is that shocks to any of the other variables can impact $\mathrm{CO}_{2}$ with a minimal delay of 1 month. In contrast, $\mathrm{CO}_{2}$ can impact any variable in the system contemporaneously, in the short/ medium/long run, or both.

In the spirit of many medium to large BVAR applications to macroeconomic data (Bernanke et al. 2005; Christiano et al. 1999; Stock and Watson 2005; Banbura et al. 2010), we classify the variables describing the internal climate variability into fast-moving and slow-moving ones. TCC, PR, and AT are classified as fast-moving. Absorbing shortwave and longwave radiation, clouds have a significant impact on Earth's energy balance and thus its overall heat content (Carslaw et al. 2002). But clouds eventually carry precipitation with not unambiguously determined effects on SIE (Parkinson and Comiso 2013; Meier et al. 2014). We order both variables before the temperature variables AT and SST. Besides AT, also SST, especially warmer water from the Atlantic Ocean, contributed to shaping the historically unprecedented decline of SIE over the last four decades (Meier et al. 2014). Here, we follow Parkinson and Comiso (2013), who state that besides the cooling effects of a melting ice cover, SST is highly influenced by currents and winds, transferring warmer energy from lower to higher latitudes. We therefore place SST at the boundary of fast- and slow-moving variables.

The last block of variables comprises SIE, SIT, and albedo. SIT is an underestimated determinant of how SIE reacts to both external forcing and internal variability (Meier et al. 2014; Parkinson and Comiso 2013). Thicker layers make the ice more resilient and increase albedo, while thin ice is more easily advected by winds, making SIE more sensitive to extreme events (Meier et al. 2014). We order SIT and albedo after SIE because we hypothesize that the effect of shocks of the former can only influence the latter with a certain delay. For instance, shocks to

\footnotetext{
${ }^{12}$ Moreover, when possible, the robustness of results to some reasonable alterations of the ordering should be assessed.

${ }^{13}$ Meier et al. (2014) give an in-depth description of the various internal factors, their mutual interaction, and their response to carbon dioxide.
} 
SIT via increased water precipitation or strong winds will immediately reduce SIT but SIE only with a certain lag. Last, we regard albedo as being driven contemporaneously by all other factors.

To wrap up, it is worth re-emphasizing that identification, via the described ordering, is necessary to interpret and understand the mechanisms captured by the VARCTIC. However, ordering choices does not alter forecasts. Mechanically, this happens because the potentially contentious matrix $\mathbf{A}$ does not enter the forecasting Eq. (4).

\section{2) ON POTENTIALLY EXCLUDED MECHANISMS}

We consider VARCTIC 18 in part to confirm that the key channels are already accounted for in VARCTIC 8. For example, studies have emphasized the role of incoming long and shortwave radiation and their interactions with SIE and SIT (Burt et al. 2016; Dai et al. 2019). The impact of downwelling longwave radiation (DLW) on SIE is not direct, but transmitted via DLW's influence on AT. Here, thickness of sea ice is crucial, as thinner ice is more susceptible to DLW than thicker layers (Park et al. 2015). As we will show later (as in Fig. B1), accounting for both shortwave and longwave radiation in VARCTIC 18, the forecast of an ice-free Arctic deviates only marginally from the ice-free date projected by VARCTIC 8. This result suggests that shortwave and longwave radiation do not impact SIE directly, but rather affect the evolution of the Arctic's sea ice cover via other variables (e.g., AT and SIT), which VARCTIC 8 already accounts for. In a similar line of thought, upper-ocean heat content may also influence to the evolution of SIE. Studies have found that anomalies in the temperature of the upper-ocean layers and anomalies in SST do coincide (Park et al. 2015), making an extension of both VARCTIC models dispensable.

However, it is not excluded that some nonlocal processes (e.g., poleward atmospheric heat transport) do contribute to sea ice loss through channels not represented in both VARCTICs. As stated earlier, we opted for including local processes only (in addition to $\mathrm{CO}_{2}$ ) because this makes the VARCTIC a complete system where all $M$ variables are internally modeled and forecasted jointly. Adding nonlocal processes raises the additional question of how to model their external dependence, a complication left for future research. $^{14}$

\section{d. Impulse response functions}

Since Sims (1980), the dominant approach for studying the properties of the VAR around its deterministic path has been impulse response functions (IRFs) to structural shocks. Thanks to the orthogonalization strategy discussed in section $3 \mathrm{c}$, we converted plain regression residuals into orthogonal shocks. ${ }^{15}$ The dynamic effect of these specific disturbances (the impulse)

\footnotetext{
${ }^{14}$ The literature on global VARs could provide a natural place to start (Pesaran et al. 2009).

${ }^{15}$ Mathematically, we took a linear combination of the VAR residuals (an unpredictable change in a variable of interest, $\mathbf{u}_{t}$ ) such that $\mathbf{u}_{t}=\mathbf{C} \varepsilon_{t}$.
}

can be analyzed as that of a randomly assigned treatment. ${ }^{16}$ Uncorrelatedness of $\varepsilon_{m, t}$ implies that the "keeping everything else constant" interpretation-hence, a causal meaning for IRFs-is guaranteed by construction.

It is natural to wonder about the meaning of uncorrelated shocks in a physical system. Mechanically, these shocks are the difference between the realized state of a variable and its predicted value as per the previous state of the dynamic system. These unpredictable anomalies, which emerge from outside a well-specified VARCTIC, are the key to understanding the dynamic properties of the model. A now-obvious example of a shock will be that of $\mathrm{CO}_{2}$ emissions reduction in 2020: it is inevitable that the observed emissions will be lower than what was predicted by the endogenous system since the latter excludes "pandemics" as a factor. Any model that is partially incomplete will be subject to external shocks. The study of such exogenous impulses may be alien-sounding, especially when contrasted with the deterministic environment of a climate model. Nonetheless, understanding the properties of a climate model by conditioning on a particular RCP scenario is equivalent to conditioning on a series of shocks. Hence, one can understand the VARCTIC and its IRFs as expanding the number of potentially exogenous sources of forcing. Of course, our later focus on $\mathrm{CO}_{2}$ shocks is expressively motivated by the fact that the latter is a well-accepted source of exogenous forcing in climate systems.

The impulse response function of a variable $m$ to a one standard deviation shock of $\varepsilon_{\tilde{m}, t}$ is defined as

$\operatorname{IRF}(\tilde{m} \rightarrow m, h)=E\left(y_{m, t+h} \mid \mathbf{y}_{t}, \varepsilon_{t, \tilde{m}}=\sigma_{\varepsilon_{\tilde{m}}}\right)-E\left(y_{m, t+h} \mid \mathbf{y}_{t}, \varepsilon_{t, \tilde{m}}=0\right)$.

Thus, it is the expected difference, $h$ months after "impact," between an Arctic system that responded to an unexpected $\mathrm{CO}_{2}$ increase and the same system where no such increase occurred. In a linear VAR with one lag $(P=1)$, the IRF of all variables can easily be computed from the original estimates using the formula

$$
\operatorname{IRF}(\tilde{m} \rightarrow m, h)=\boldsymbol{\Psi}^{h} \mathbf{A}^{-1} \mathbf{e}_{\tilde{m}},
$$

where $\mathbf{e}_{\tilde{m}}$ is a vector with $\sigma_{\varepsilon_{\tilde{m}}}$ in position $\tilde{m}$ and zero elsewhere. This just means that we are looking at the individual effect of $\boldsymbol{\varepsilon}_{\tilde{m}}$ while all of the other structural disturbances are shut down. ${ }^{17}$

The latter discussion focused on analyzing how our dynamic system responds to an external/unforeseeable impulse, which is a standard way of interpreting VAR systems. Of course, we are also interested in the "systematic" part of the VAR that is responsible for the propagation of shocks when they do occur-the IRF transmission mechanism. In section $4 \mathrm{c}$, we

\footnotetext{
${ }^{16}$ Of course, one could look at how the system responds to an impulse from a residual $u_{m, t}$, but the interpretation will be rather weak because those are correlated across equations.

${ }^{17}$ In the case of a linear VAR with $P>1$ lags, we must use the companion matrix form.
} 
focus our attention on $\mathrm{CO}_{2}$ and $\mathrm{AT}$ shocks and quantify the amplification effect of different channels.

\section{e. Bayesian estimation}

We use a Bayesian VAR in the tradition of Litterman (1986). There are two crucial advantages of doing so. First, Bayesian inference does not depend on whether the VAR system is stationary or not (Fanchon and Wendel 1992). We are effectively modeling variables in levels and expecting at least one explosive root. Frequentist inference is notoriously complicated in such setups (Choi 2015) and even standard approaches for nonstationary data have well-known robustness problems (Elliott 1998). From a practical point of view, using nonstationary data means that standard test statistics (like Granger causality tests) will be undermined by faulty standard errors, potentially leading to erroneous conclusions.

Second, for us to consider a system of many variables estimated with a relatively small number of observations, Bayesian shrinkage can be beneficial to out-of-sample forecasting performance and help in reducing estimation uncertainty (like those of IRFs). In fact, VARs are known to suffer from the curse of dimensionality as the number of parameters scales up very fast with the number of endogenous variables. ${ }^{18}$ Via informative priors, Bayesian inference provides a natural way to impose soft/stochastic constraints (i.e., constraints are not imposed to bind) and yet keeps inference possible (Banbura et al. 2010). ${ }^{19}$ Furthermore, we are interested in transformations (forecasting paths, impulse response functions) of the parameters rather than the parameters themselves. Inference for such objects can easily be obtained by transforming draws from the posterior distribution. All of these procedures are well established in the macroeconometrics community and packages are available in most statistical programming software (Dieppe et al. 2016). An extended discussion of the prior and its motivation for time series data and details on the exact values of (data-driven) hyperparameters used can all be found in appendix A.

Finally, the maximal lag order of the VAR, $P$ in Eqs. (3) and (2), must be chosen. ${ }^{20}$ Its selection is yet another incarnation of the bias-variance trade-off. We fix the number of lags in VARCTIC 8 to $P=12$ and to $P=3$ in VARCTIC 18 respectively. This choice is based on the deviance information criterion (DIC) - the Bayesian analog to popular information criteria used for model selection. Accordingly, the superior VARCTIC 8 would set $P=3$ (DIC $=-6988),{ }^{21}$ a choice that only provides a marginal improvement with respect to $P=12$ $(\mathrm{DIC}=-6894) .{ }^{22}$ Since structural analysis is an essential part

\footnotetext{
${ }^{18}$ Such a situation motivates McGraw and Barnes (2020) to use the LASSO.

${ }^{19}$ For instance, running a VAR with LASSO would induce some form of shrinkage but inference is far from easy.

${ }^{20}$ To re-emphasize, this means $y_{t-p}$ for $p=1, \ldots, P$ are included.

${ }^{21}$ The lower, the better.

${ }^{22}$ Additionally, the reported DIC for $P=12$ is superior to other natural candidates such as $P=1$ and $P=24$.
}

of this paper, we err on the side of having slightly higher variance, but potentially richer dynamics for IRFs. In the large VARCTIC 18, the need for shrinkage is magnified and $P=3$ is the obvious more reasonable choice.

An extraneous question, which can benefit from verification by DIC, is whether trends should be included. We hypothesize that VARCTIC 8 is a complete, divergent system that can endogenously explain the trending behavior of all its variables by the joint action of $\mathrm{CO}_{2}$ forcing and feedback loops. If that were not to be true, including linear trends would noticeably improve model fit and lower the DIC even further. Backing our claim that the VARCTIC needs no additional (and hardly climatically explainable) statistical crutch, the DIC from including trends is worse (now DIC $=-6817$ for VARCTIC 8) than that of the original model.

\section{Results}

A VAR contains many coefficients: there are $8 \times(8 \times 12+$ $1)=776$ in the baseline VARCTIC. ${ }^{23}$ Staring at them directly is unproductive and a single coefficient (or even a specific block) carries little meaning by itself. As it is common with VARs in macroeconomics, we rather study the properties of the VARCTIC by looking at its implied forecasts and its IRFs.

\section{a. The "business as usual" forecast}

We report here the unconditional forecast of our main VARs. VARCTIC 8 suggests SIE to hit the zero lower bound around 2060 (see Fig. 2), whereas VARCTIC 18 projects the Arctic to be ice-free at about the same time (see Fig. 7). ${ }^{24}$ The shaded area shows $90 \%$ of all the potential paths of the respective VARCTIC. That is, VARCTIC 8 dates the Arctic to be totally ice-free for the first time somewhere between 2052 and 2073 with a probability of $90 \%$. VARCTIC 18 slightly extends that time frame to the year 2079.

For the two models, the median scenario has SIE being less than $1 \times 10^{6} \mathrm{~km}^{2}$ by 2054 and 2060 , respectively. The result $1 \times$ $10^{6} \mathrm{~km}^{2}$ is more likely an interesting quantity since the "regions north of Greenland/Canada will retain some sea ice in the future even though the Arctic can be considered as 'nearly sea ice free' at the end of summer', (Wang and Overland 2009, p. 3). The corresponding credible regions mark the period 2047-65 for VARCTIC 8 and 2047-69 for VARCTIC 18, respectively. These dates and time spans range in the close neighborhood of previous climate model simulations (Jahn et al. 2016). For both VARCTICs, less than $5 \%$ of the simulated paths hit 0 before 2050, making it an unlikely scenario according to our calculations. In essence, the two models suggest SIE melting at a rate that is slower than Diebold and Rudebusch's (2021) results, but

\footnotetext{
${ }^{23}$ The same arithmetic gives a total of 990 parameters in VARCTIC 18.

${ }^{24} \mathrm{We}$ include in the graph the in-sample deterministic component of the VAR [as discussed in Giannone et al. (2019)], which is essentially a long-run forecast, starting from 1980 (the same sort of which we are doing right now for the next decades) using the VAR estimates of 12 lags.
} 


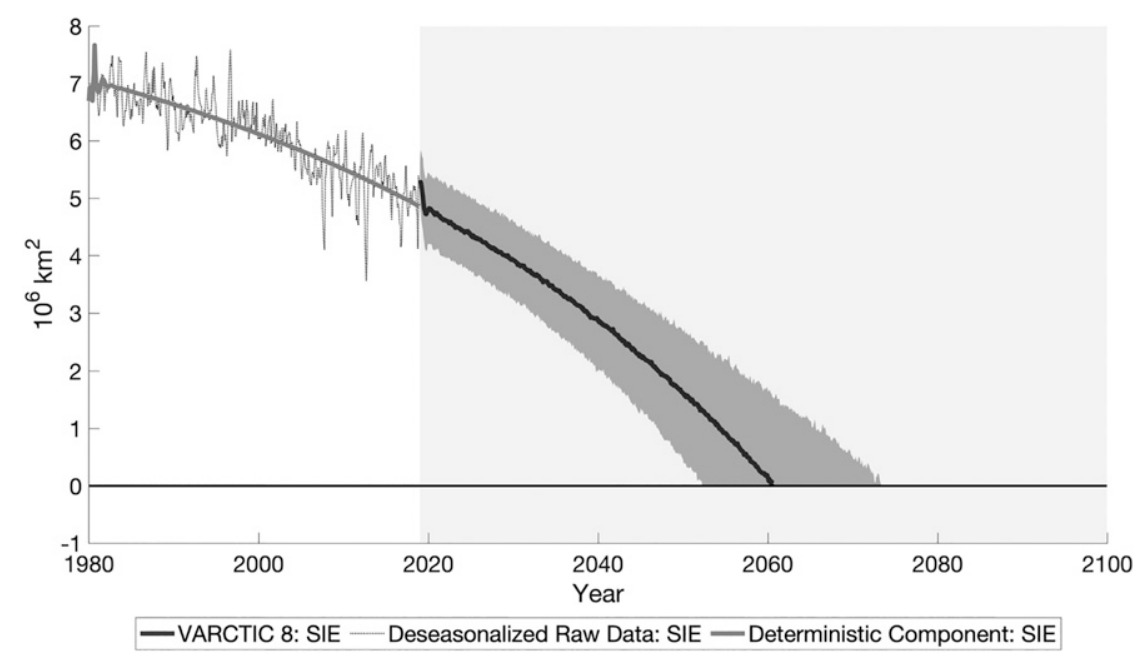

FIG. 2. Trend of sea ice extent for September. Shading indicates the $90 \%$ credible region.

much faster than most CMIP5 models (Stroeve et al. 2012), and in line with the latest CMIP6 calculations (Notz et al. 2020). ${ }^{25}$

Nonetheless, it is natural to ask how much we can trust a forecast made 40 years ahead, based on 40 years of data behind. To a large extent, answering this amounts to cataloging what types of uncertainty the $90 \%$ credible regions incorporate and those they do not. These reflect both forecasting uncertainty (the presence of shocks) and parameter uncertainty. The latter means the $90 \%$ regions reflect what happens to the spread of forecast paths when small disturbances are incorporated in the (estimated) coefficient matrix. In other words, those bands conveniently (and correctly) quantify prediction uncertainty accounting for the fact that we are iterating something that is estimated. All things considered, uncertainty is correctly calibrated as long as the model is correctly specified. As is the case with any statistical approach, the VARCTIC necessarily assumes that the physical reactions estimated on the previous decades' data remain valid for those to come. Thus, if the future holds unprecedented nonlinear mechanisms or previously undetectable relationships, ${ }^{26}$ the VARCTIC can hardly accommodate for that. In contrast, any intensification of phenomena characterized by our eight key variables (like albedo feedback) should be successfully captured out of sample. With VARCTIC results being in accord with the recent CMIP6 consensus, our specification seems to capture the main drivers and dynamics of the Arctic ecosystem. ${ }^{27}$ Finally,

\footnotetext{
${ }^{25}$ Note that augmenting VARCTIC 8 with other greenhouse gases such as methane $\left(\mathrm{CH}_{4}\right)$ procures near-identical results (i.e., forecasting and forthcoming IRFs). This reinforces the view that $\mathrm{CO}_{2}$ plays a distinct and important role in determining the fate of SIE.

${ }^{26}$ Notz and Stroeve (2016) find that in nearly all CMIP5 models, the negative relationship between $\mathrm{CO}_{2}$ and SIE was not prevalent until the second half of the twentieth century.

${ }^{27}$ However, we acknowledge recent research, which stresses the role of ozone-depleting substances (ODS) - another form of anthropogenic greenhouse gases-in the warming of the Arctic region over the last decades (Polvani et al. 2020).
}

future $\mathrm{CO}_{2}$ emissions are an uncontested source of uncertainty for long-run SIE forecasts. Section 4d studies how those (and their credible regions) behave under standard forcing scenarios.

\section{b. Impulse response functions}

Figure 3 displays impulse response functions, that is, the response of SIE to a positive shock of one standard deviation to any of the model's $M$ variables. To reflect parameter uncertainty, we additionally report the $90 \%$ credible region for each IRF. This means the gray bands contain $90 \%$ of the posterior draws from VARCTIC 8. Those are crucial in determining whether the attached IRFs describe significant physical phenomena or not. Particularly, when the credible region extends to both positive and negative sides, the IRF characterizes a phenomenon of negligible importance. In those instances (e.g., many IRFs at horizon $h>24$ months), the posterior mean's (black line) difference from 0 could merely be due to parameter uncertainty, and can be thought of as approximately 0 .

The resulting impact of $\mathrm{CO}_{2}$ anomalies on SIE is sizable and most importantly, durable. While the sign of the response is highly uncertain and weak for more than a year, $\mathrm{CO}_{2}$ shocks emerge to have a lasting downward effect on SIE. The relevance of the $\mathrm{CO}_{2} / \mathrm{SIE}$ relation is not a surprise (Notz and Stroeve 2016). Moreover, this behavior is distinct from other shocks that have a significant short-run effect but no significant effect after more than roughly six months. More precisely, the effect of $\mathrm{CO}_{2}$ impulses takes more than a year to settle in (not significant for approximately 15 months) but ends up having a continuing downward effect on trend SIE of approximately $-0.005 \times 10^{6} \mathrm{~km}^{2}$. This mechanically implies that a one-off $\mathrm{CO}_{2}$ deviation from its predicted value/trend leads to a $\mathrm{cu}$ mulative impact that is ever increasing in absolute terms (as displayed later in Fig. 4b). It is important to remember that this is the effect of an unexpected increase in $\mathrm{CO}_{2}$. This is to be contrasted with the systematic effect that will be studied later. However, in the framework of this section-where $\mathrm{CO}_{2}$ is 

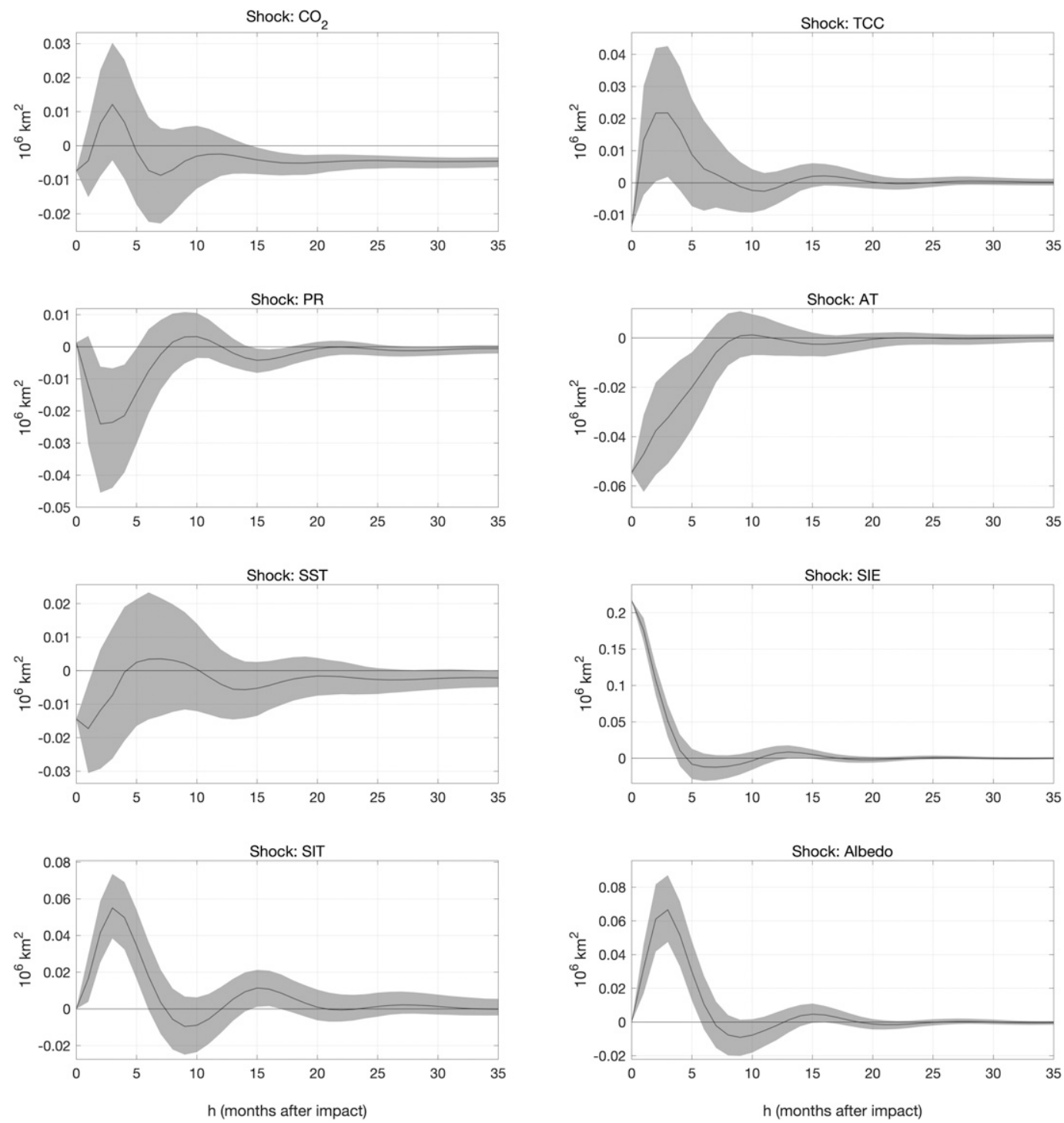

FIG. 3. IRFs: Response of sea ice extent. Shading indicates the $90 \%$ credible region.

allowed to endogenously respond to Arctic variables-this is as close as one can get to obtain an experimental/exogenous variation needed to evaluate a dynamic causal effect. The value of $-0.005 \times 10^{6}$ is roughly $0.1 \%$ of the last deterministic trend value of SIE. $\mathrm{CO}_{2}$ shocks, by construction of our linear VAR, have mean 0 and there are approximately as many positive and negative shocks in sample. The linearity and symmetry of the VAR imply that these durable effects are present for both upward and downward deviations from the deterministic trend.

Other shocks have sizeable impacts that eventually vanish, which is the traditional IRF shape one would expect to see from a VAR on macroeconomic data. For instance, AT and albedo IRFs clearly have the expected sign. However, they do not have the striking lasting impact of $\mathrm{CO}_{2}$ perturbations. To rationalize the short-lived IRF $(\mathrm{AT} \rightarrow \mathrm{SIE})$, it is worth re-emphasizing what is meant by an AT shock. It is an AT anomaly that is not explicable by (i) the previous state of the system or (ii) other structural shocks ordered before it $\left(\mathrm{CO}_{2}\right.$, TTC, PR). As an example, one could think of the 2007 record low SIE (at that time) being attributed to an abnormally high "atmospheric flow of warm and humid air" from lower latitudes into the Arctic region (Graversen et al. 2011, p. 2103). As we will see in section $4 \mathrm{c}$, a $\mathrm{CO}_{2}$ shock triggers (with a significant delay) a persistent increase in AT, which eventually impacts SIE downward through the systematic part of the VAR. Thus, the short-lived response of SIE to AT shocks does not rule out a lasting impact of AT on SIE. Rather, it means that when it occurs, the origin of the anomaly is not AT itself, but likely $\mathrm{CO}_{2}$.

Similar to an unforeseeable AT shock, a one-time albedo shock will not have a lasting effect on SIE either. This does not preclude albedo amplifying other shocks, as we will see in the 


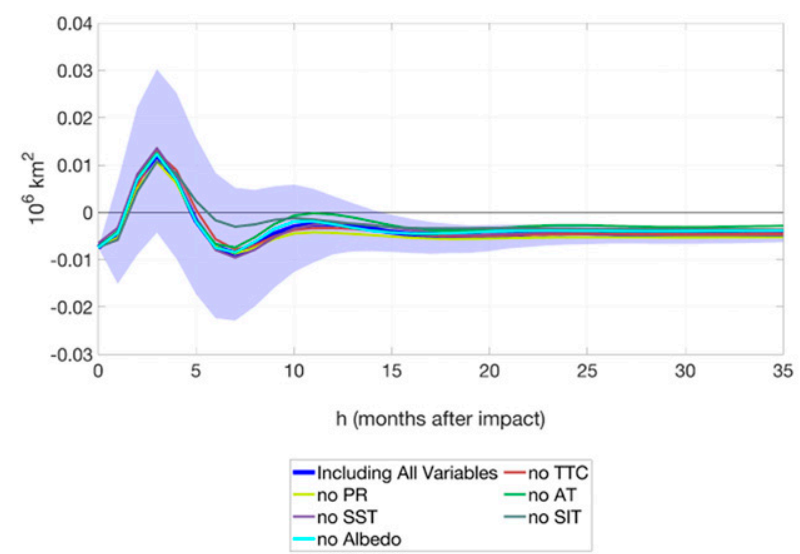

(a) Shock of $\mathrm{CO}_{2}$ on SIE

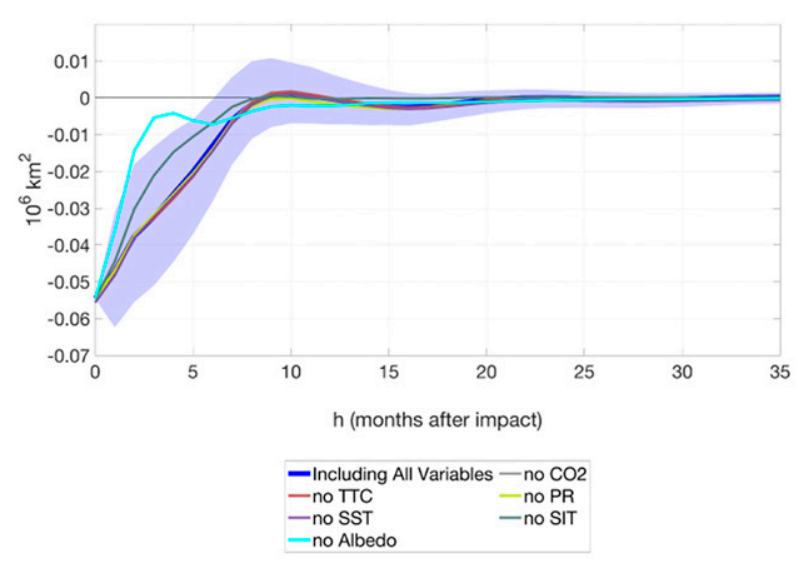

(c) Shock of AT on SIE

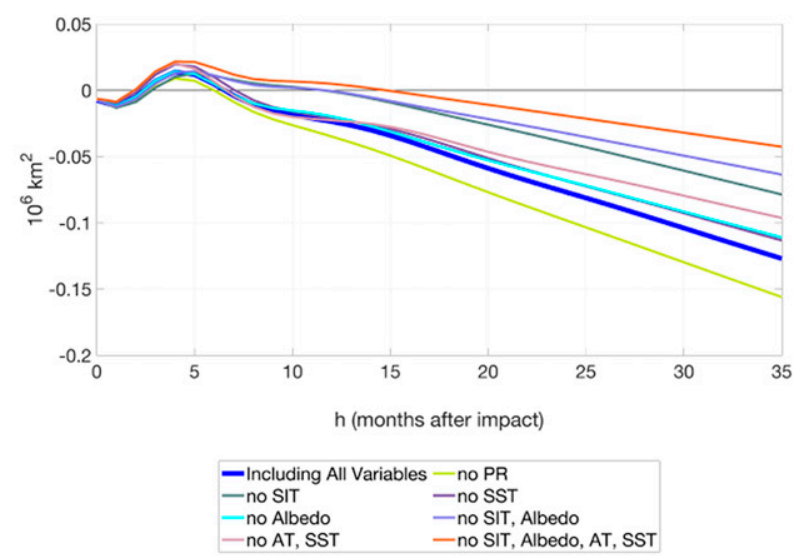

(b) Shock of $\mathrm{CO}_{2}$ on SIE - cumulative

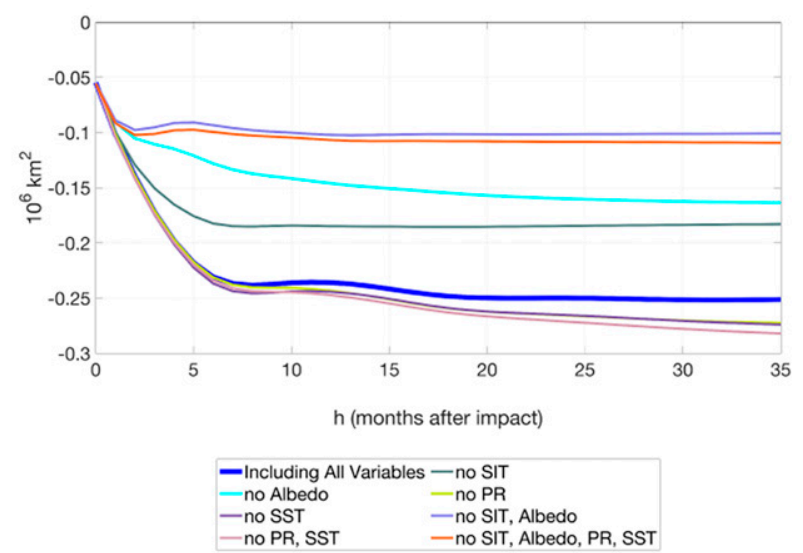

(d) Shock of AT on SIE - cumulative

FIG. 4. IRF decomposition: Response of sea ice extent. Shading indicates the $90 \%$ credible region for the original IRF.

next section. ${ }^{28}$ Finally, a rightful concern is whether IRFs remain unaltered upon sensibly altering the ordering of section 3c. To a large extent, they do. For instance, placing SST and AT before TCC and PR brings no noticeable change, and so does moving albedo from last to second.

\section{c. Amplification of $\mathrm{CO}_{2}$ and temperature shocks by feedback loops}

The melting of SIE is happening much faster than many other phenomena that are also believed to be set in motion by the steady increase of $\mathrm{CO}_{2}$ emissions. Many recent papers (Notz and Marotzke 2012; Wang and Overland 2012; Serreze and Stroeve 2015; Notz 2017) argue with theory/climate models or correlations that external $\mathrm{CO}_{2}$ forcing is responsible for the long-run trajectory of SIE. Some of these findings led Notz and Stroeve (2016) to conclude that climate models severely underestimate the impact of $\mathrm{CO}_{2}$ on SIE.

A rather consensual view is that the very nature of the Arctic system leads to the amplification of such external forcing

\footnotetext{
${ }^{28}$ For a discussion of VARCTIC 18 results, see appendix B.
}

shocks. An understanding from observational data on how the Arctic may or may not amplify certain external forces is still pending. Fortunately, a VAR can quantify the contribution of different variables in explaining how a dynamic system responds to an external impulse.

\section{1) Methodology}

A potential approach that has a long history in econometrics is the use of Granger causality (GC) tests. Those consist of evaluating predictive causal statements (such as $\mathbf{X}_{t-1} \rightarrow \mathbf{Y}_{t}$ and $\left.\mathbf{Y}_{t-1} \rightarrow \mathbf{X}_{t}\right)$ via significance tests in time series regressions. They have been recently advocated for climate applications by McGraw and Barnes (2018). Nevertheless, those tests often fall short of answering questions of interest. First, the meaning of the test is not obvious when more than two variables are included and/or if one is interested in multihorizon impacts. Second, in the wake of a GC test rejection, the block of reduced-form coefficients, ${ }^{29}$ which we know to be of some

\footnotetext{
${ }^{29}$ Precisely, we mean coefficients on lags of $\mathbf{X}_{t}$ in a regression of those on $\mathbf{Y}_{t}$ (including lags of $\mathbf{Y}_{t}$ as well).
} 
statistical importance, is very hard to interpret. In other words, we know some channel matters, but we have little idea how it matters. $^{30}$

In light of the above, we rather opt for IRF decomposition. As the name suggests, the physical reaction characterized by IRFs will be decomposed as a sum of transmission channels to determine which contributions' magnitudes and signs are directly informative. Less abstractly, the consequential negative response of SIE to $\mathrm{CO}_{2}$ shocks is likely composed of a direct effect and many entangled indirect effects (e.g., that of AT and albedo). Understanding those in the dynamic setup of a VAR is much more intricate than in a static regression setting. This is so because, for horizons greater than one, IRFs are obtained by iterating predictions, which means $\mathbf{X}$ can impact $\mathbf{Y}$ through $\mathbf{Z}$, but also through any of its lags. We employ a strategy that has been used in macroeconomics to better understand the transmission mechanism in VARs. It consists rather simply of shutting down "channels" and plotting what the response to a shock would be, given that this very channel had been shut (Sims and Zha 2006; Bernanke et al. 1997; Bachmann and Sims 2012). We can deploy this methodology to find and quantify the most important channels through which $\mathrm{CO}_{2}$ and temperature shocks impact SIE.

\section{2) AMPLIFICATION OF $\mathrm{CO}_{2}$ SHOCKS}

For VARCTIC 8, Figs. 4a and 4b show the responses of SIE to an unexpected increase in one standard deviation of $\mathrm{CO}_{2}$. The blue line pictures the case of the baseline VARCTIC 8 with $90 \%$ credible region. The remaining six lines show the response of SIE to the same shock but shutting down key transmission channels. In terms of implementation, it consists of imposing hypothetical shocks to one of the other variables, which offsets their own response to a $\mathrm{CO}_{2}$ shock. ${ }^{31}$

The top panel of Fig. 4 reveals the importance of temperature (especially AT) in translating $\mathrm{CO}_{2}$ anomalies into decreasing SIE, without great surprise. That is, we observe that shutting down these channels leads to a smaller absolute response, which means that those variables can be considered as amplification channels. Given the atypical shape of the $\mathrm{CO}_{2}$ IRF, the scale of Fig. 4a makes less visible the action of channels that only alter the longer-run effect. Since those effects are durably negative (at different levels), their cumulative effect will more clearly reveal their relative importance. Thus, Fig. 4b displays the cumulative impact of selected (more important) channels. The two temperature channels are responsible for approximately one-fourth of the cumulative effect of $\mathrm{CO}_{2}$ on SIE after 3 years. More precisely, restricting temperature variables to not respond to a positive $\mathrm{CO}_{2}$ shock decreases (in absolute terms) the impact after 3 years from $-0.13 \times 10^{6}$ to $-0.1 \times 10^{6} \mathrm{~km}^{2}$. Of course, it was expected

\footnotetext{
${ }^{30}$ Similar concerns led us to discard Liang's (2014) quantitative causality since the currently available formula only applies to bivariate systems. Further, it does not allow for contemporaneous relationships, which are clearly present in our application (and a feature of almost any discretely sampled multivariate time series).

${ }^{31}$ See Bachmann and Sims (2012) for details.
}

that temperature should be a major conductor of such shocks. We also observe similar quantitative effects for both SIT and albedo in isolation. Most strikingly, we find that the conjunction of the albedo and SIT amplification channels is responsible for amplifying the effect of $\mathrm{CO}_{2}$ shocks by a nonnegligible $50 \%$.

The albedo amplification matches evidence reported in several studies (Perovich and Polashenski 2012; Björk et al. 2013; Parkinson and Comiso 2013) using various different methodologies. In contrast, our results for SIT amplification contribute to a literature where a consensus has yet to emerge. The ice growth-SIT feedback describes the observation that a thinning of the sea ice cover induces more rapid ice formation during winter, a compensating effect that slows down melting (Bitz and Roe 2004; Goosse et al. 2018). Other studies have emphasized the positive feedback between SIT and SIE, where a thinning ice cover further accelerates melting by being less resilient to climate forcing (Parkinson and Comiso 2013; Kwok 2018). Our results unequivocally support the latter to be most empirically prevalent. ${ }^{32}$ Nearly identical results are obtained when using AT, albedo, PR, and TCC averaged between $60^{\circ}$ and $90^{\circ} \mathrm{N}$ latitude, suggesting most (if not all) of the action comes from higher latitudes-hence our focus on local processes when explaining those results.

This section focused on how and why SIE responds to $\mathrm{CO}_{2}$ shocks. In section 4d, we look instead at the effect of the systematic increase of $\mathrm{CO}_{2}$ level.

\section{3) AMPLIFICATION OF AIR TEMPERATURE SHOCKS}

AT shocks are movements in AT that are not predictable given the past state of the system and are orthogonal to other shocks in the system, most notably $\mathrm{CO}_{2}$. In other words, we are looking at the effect of unexpected higher or lower AT that is uncorrelated with other shocks in the system. As we saw in Fig. 3, such AT anomalies have a pronounced short-run effect on trend SIE for no longer than 10 months after the shocks. This means that unlike $\mathrm{CO}_{2}$, the cumulative effect of AT disturbances stabilizes about 1.5 years after the event.

In Fig. 4c, we clearly observe (again) an important role for the thinning of ice and the albedo effect amplifying the response of SIE to AT shocks. In fact, we see in Fig. 4d that without them, the long-run impact is the same as the instantaneous one. Thus, this is evidence to suggest that the AT shock's long-run cumulative impact of $-0.24 \times 10^{6} \mathrm{~km}^{2}$ is mostly a result of the action of feedback loops.

\section{d. Forecasting SIE conditional on $\mathrm{CO}_{2}$ emissions scenarios}

If $\mathrm{CO}_{2}$ 's trend is mostly or solely affected by factors outside of those considered in the VAR, the forecast of SIE can be improved by treating $\mathrm{CO}_{2}$ forcing as exogenous and using an external forecast rather than the one internally generated by the VAR. Conditional forecasting can be achieved in VARs

\footnotetext{
${ }^{32}$ It is plausible that the ice growth-SIT feedback explains why both IRF (SIT $\rightarrow$ SIE) (Fig. 3) and SIT's influence on IRF $\left(\mathrm{CO}_{2} \rightarrow\right.$ SIE) (Fig. 4) take over 6 months to completely settle in-its seasonal character dampens the (early) positive feedback effect.
} 


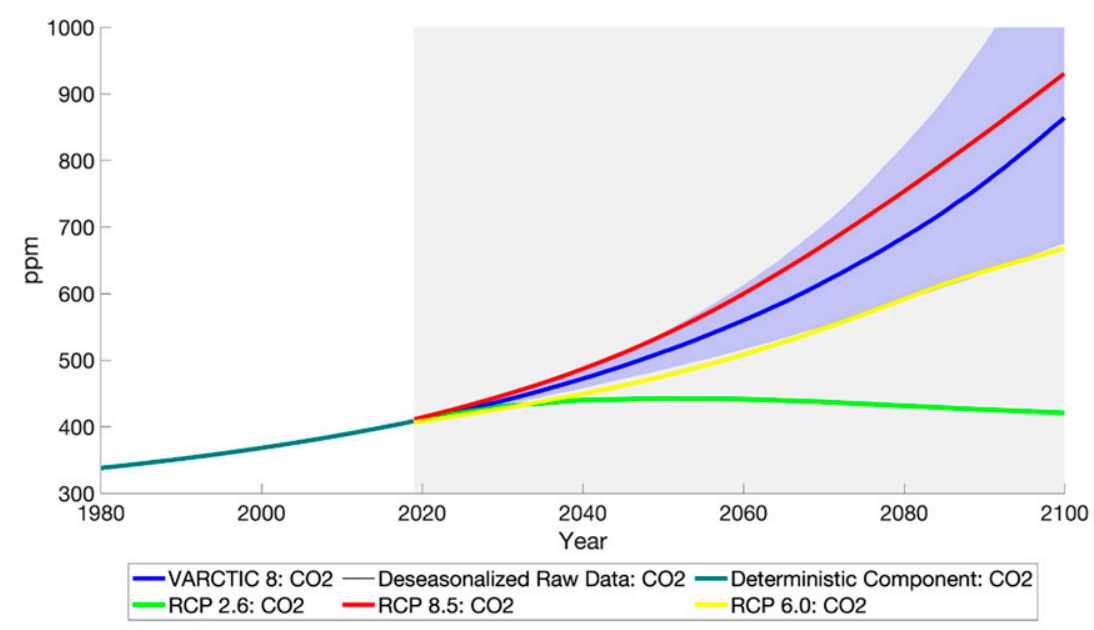

(a) Evolution of $\mathrm{CO}_{2}$ emissions until the End of the Century under different Scenarios

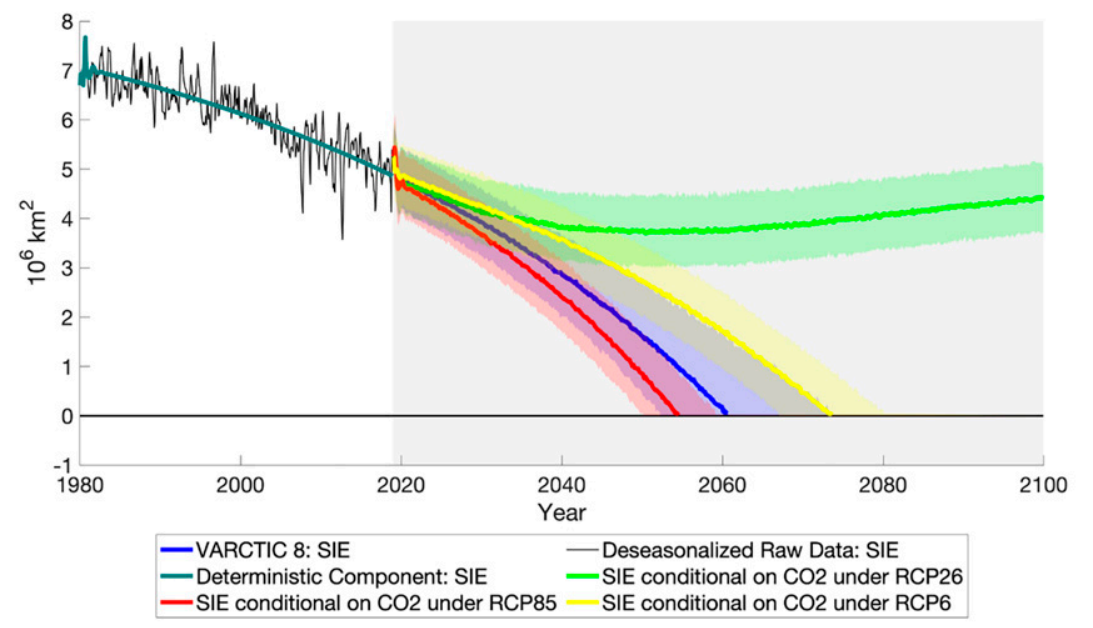

(b) Evolution of SIE under different Scenarios of $\mathrm{CO}_{2}$

FIG. 5. VARCTIC projections and different RCPs. Shading indicates $90 \%$ credible region.

following the approach of Waggoner and Zha (1999). As we will see, this will markedly sharpen the bands around our forecasts, suggesting that a great amount of uncertainty is related to the future path of $\mathrm{CO}_{2}$ emissions. Additionally, this brings the VARCTIC conceptually closer to standard analyses on the future of the Arctic (Stroeve et al. 2012; Stroeve and Notz 2018; Notz et al. 2020).

In the spirit of Sigmond et al. (2018), who constrain the levels of AT in their climate model, we will look at $\mathrm{CO}_{2}$ emissions under three different representative concentration pathways (RCPs) and investigate their impact on the evolution of Arctic sea ice. Figure 1 shows a steady increase in $\mathrm{CO}_{2}$ emissions over the last three decades, but several RCPs paint different pictures for the trajectory of carbon emissions until the end of the century. Figure 5a shows the different paths of $\mathrm{CO}_{2}$ under RCP2.6, RCP6, and RCP8.5, as well as the projected path following VARCTIC 8. Most interestingly, we find our completely endogenous and unconditional forecast of $\mathrm{CO}_{2}$ to lie somewhere between the "very bad" RCP8.5 scenario and the "business-as-usual" RCP6 one.

Figure 5b shows VARCTIC 8's projection of Arctic SIE when conditioning the out-of-sample path of $\mathrm{CO}_{2}$ on the three different RCP scenarios. For reference, the figure also includes projected SIE with the future path of $\mathrm{CO}_{2}$ endogenously determined within the model, as discussed above. The pictured effect is dramatic: if emissions were reduced as to follow the RCP2.6 scenario, whose $\mathrm{CO}_{2}$ emissions are still at the higher boundary of what the Paris Agreement demands, the Arctic would be far from blue and would even recover earlier losses by the end of the century. If emissions follow the more likely RCP6, SIE would vanish later than projected by the unconditional VARCTIC 8, but would still be completely gone during the 2070s. In the worst-case scenario, RCP8.5, we obtain an icefree September by the mid-2050s. Interestingly, this result is 
very close to what Stroeve and Notz (2018) reported using a very different methodology (extrapolating a linear relationship). Their bivariate ( $\mathrm{SIE}$ and $\mathrm{CO}_{2}$ ) analysis suggests the Arctic summer months to be ice-free by 2050 . However, in contrast, our results are much more optimistic than theirs in terms of SIE conditional on the (rather unlikely) RCP2.6 scenario. Such analysis is not conditional on the identification scheme since it is based solely on the reduced form. ${ }^{33}$ Overall, these results reinforce the view that anthropogenic $\mathrm{CO}_{2}$ is the main driver behind the current melting of SIE as well as the main source of uncertainty around the future SIE path. Furthermore, the optimistic RCP2.6 results suggest that internal variability by itself cannot lead to the complete melting of SIE, even when starting from today's level. Overall, the VARCTIC yields similar conclusions about the importance of $\mathrm{CO}_{2}$ to that of Dai et al. (2019) and Notz and Stroeve (2016). It is reassuring to see that climate models' conclusions can be corroborated by a transparent approach that relies solely and directly on the multivariate time series properties of the observational record.

\section{e. Amplification effects in the projection of SIE under different RCPS}

The previous section documented the evolution of SIE conditional on several $\mathrm{CO}_{2}$ trajectories, treating the latter as an exogenous driver. This section seeks to quantify the importance of feedback effects when it comes to translating an RCP path into SIE loss. That is, we attempt to quantify to which extent the albedo and SIT effects can be held responsible for amplifying the impact of $\mathrm{CO}_{2}$ forcing and thus accelerating the melting of SIE.

Following the findings of section $4 \mathrm{c}$, in which we identified SIT and albedo to carry potential for mitigating the adverse influence of $\mathrm{CO}_{2}$ on SIE, we ask the question about how SIE would evolve, if SIT and albedo were to remain constant at a certain level over the forecasting period. In particular, we repeat the forecasting exercise of the previous section for all three RCP scenarios, but keep SIT and albedo constant until the end of the forecasting period. For both variables we set the level equal to the value, which is given by the series' deterministic component at the end of the sample period. By doing so, we create artificial shocks to both SIT and albedo in each forecasting step, which offset their response to the external forcing variable. As we are modeling a dynamic and interconnected system, these shocks do affect all of the other variables (except for $\mathrm{CO}_{2}$ on which we condition our forecast).

Figure 6 documents the corresponding results for RCP8.5, RCP6, and RCP2.6. For each scenario, we show three different cases: (i) the projection of SIE under the respective RCP, (ii) the evolution of SIE under the respective RCP while keeping albedo constant at its last in-sample deterministic value, and (iii) the projection of SIE while keeping both albedo and SIT constant at their last respective deterministic value. The latter

\footnotetext{
${ }^{33}$ Important to note is the fact that the very last in-sample observations for $\mathrm{CO}_{2}$ even range above the RCP8.5 values, which generates the slight upward jump in case of the latter scenario.
}

are shown to be undeniable accelerants. First, fixing albedo to its 2019 value and thus shutting down this particular long-run amplification effect postpones the date of reaching $1 \times 10^{6} \mathrm{~km}^{2}$ by a bit less than a decade under both RCP8.5 and RCP6. Arctic sea ice thickness plays a major role for the reaction and resilience of SIE to anthropogenic forcing. Figure 6 reinforces this view by showing that preventing both SIT and albedo from further decay could potentially postpone the zero-SIE event to the next century under RCP6. Under RCP8.5, shutting down both amplification channels starting from 2020 leads to SIE crossing the bar of $1 \times 10^{6} \mathrm{~km}^{2}$ about a decade later. ${ }^{34}$ This feeds into the pictured nonlinearity and acceleration of SIE loss and provides a potential justification for the finding in Diebold and Rudebusch (2021) that a quadratic trend is a preferable approximation of the long-run summer months' SIE evolution.

\section{Conclusions and directions for future research}

We proposed the VARCTIC as a middle ground alternative to purely theoretical or statistical modeling. It generates longrun forecasts that embody the interaction of many key variables without the inevitable opacity of climate models. First, we focus our attention on how the Arctic system responds to exogenous impulses and propagates them. Our results show that $\mathrm{CO}_{2}$ anomalies have an unusually lasting effect on SIE, which takes about a year to settle in. It is the only impulse that has the property of durably affecting SIE. Albedo and SIT are shown to play an important role in amplifying the response of SIE to $\mathrm{CO}_{2}$ and AT shocks. In both cases, the conjunction of the two effects can double the cumulative impact of such shocks after 2 years.

Second, we focus on the systematic/deterministic part of the VARCTIC and conduct conditional forecasting experiments that again seek to quantify the effect of anthropogenic $\mathrm{CO}_{2}$ and how feedback loops can amplify it. We condition on the future path of $\mathrm{CO}_{2}$ and show that, within the context of our model, it is the prime source of uncertainty for the long-run forecast of SIE. RCP8.5 implies 0 September SIE around 2054, RCP6 says so around 2075 and finally, RCP2.6 ( Paris Accord) implies that such an event would never happen. We conclude the analysis by evaluating to which extent internal knock-on effects can amplify the long-run effect of $\mathrm{CO}_{2}$ forcing. Our results provide statistical backing for the view that $\mathrm{CO}_{2}$ shocks trigger feedbacks of other climate variables (as characterized here by albedo and SIT), which substantially accelerate the speed at which SIE is headed toward 0 .

There are many methodological extensions within the VAR paradigm that could be of interest for future cryosphere research. For instance, smooth-transition VARs [with a popular application in Auerbach and Gorodnichenko (2012)] could be used to accommodate for dynamics evolving over the seasonal

\footnotetext{
${ }^{34}$ The graphs are cut at the $1 \times 10^{6} \mathrm{~km}^{2}$ bar as keeping SIT constant (which the thought experiment suggests) is untenable as SIE approaches 0: SIT cannot be constrained to be positive if SIE is 0 .
} 


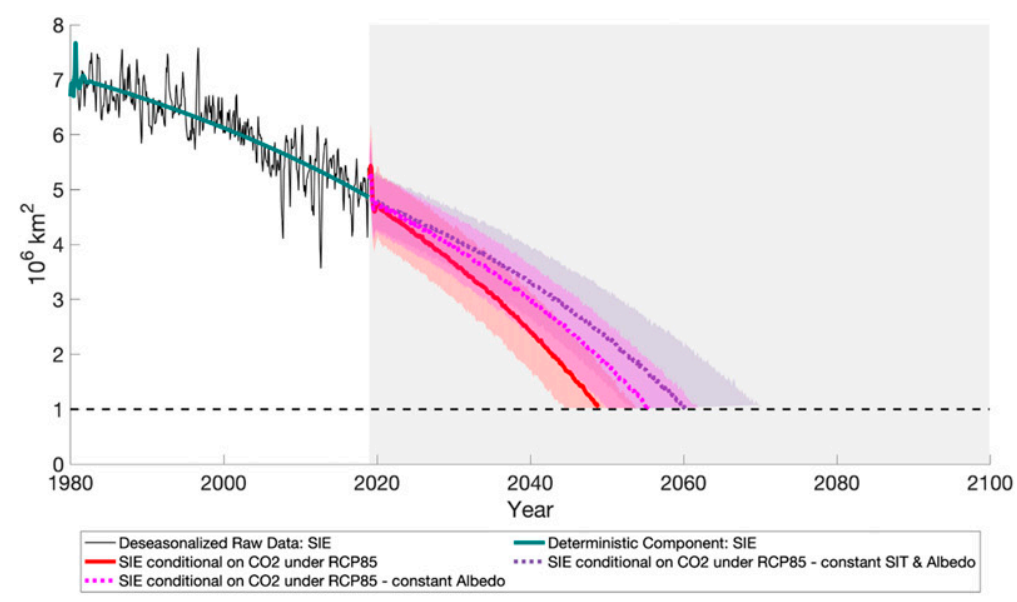

(a) $\mathrm{RCP} 8.5$

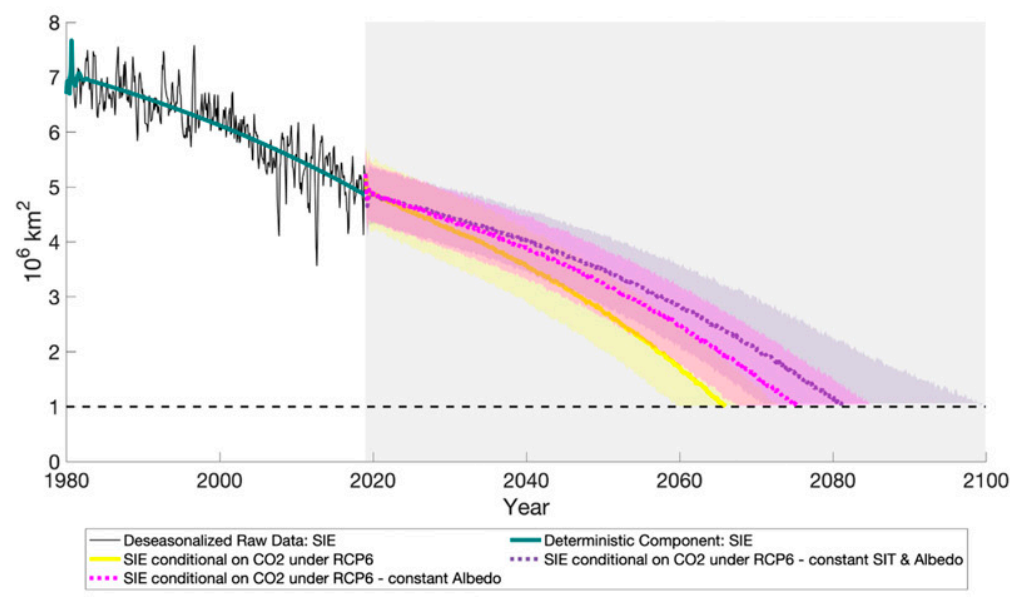

(b) $\mathrm{RCP} 6$

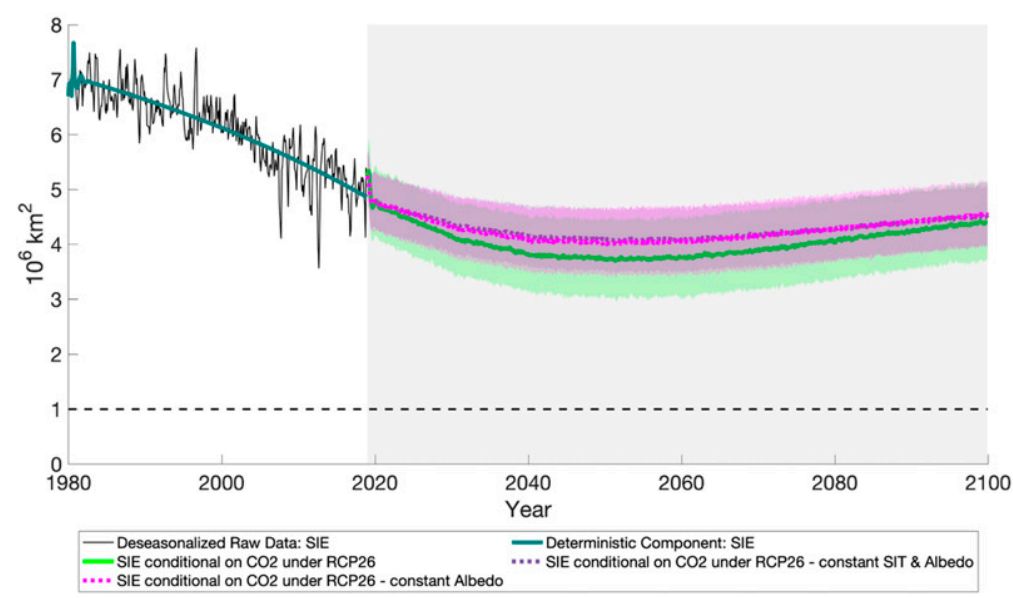

(c) $\operatorname{RCP} 2.6$

FIG. 6. Conditional forecasts with and without feedback. 


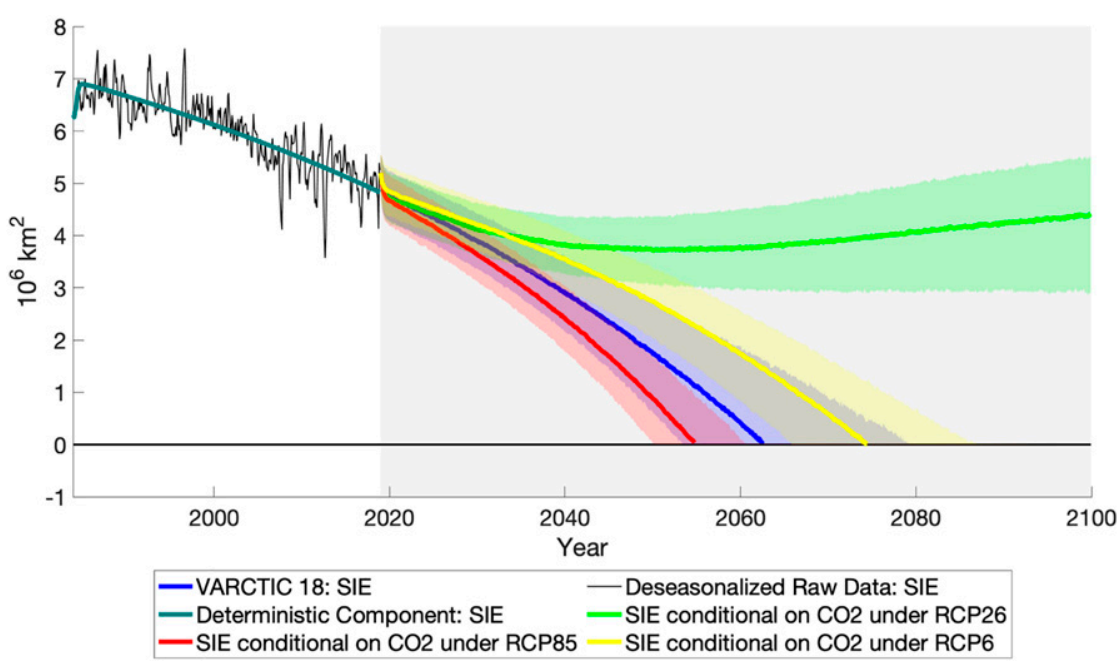

FIG. 7. Evolution of SIE different scenarios of $\mathrm{CO}_{2}$ in VARCTIC 18.

cycle. Additionally, Screen and Deser (2019) remark on the importance of changing weather phenomena that transition through decadal cycles, such as the Pacific decadal oscillation. Time-varying parameters VARs could evaluate the quantitative relevance of such phenomena. Finally, some recent attention (Chavas and Grainger 2019) has been given to the potentially nonlinear relationship between $\mathrm{CO}_{2}$ and SIE. Methods that blend time series econometrics and machine learning as in Goulet Coulombe (2020) could reveal interesting insights into complex/time-varying relationships in the Arctic.

Acknowledgments. For helpful discussions and comments on earlier drafts, we thank Edvard Bakhitov, Elizaveta Brover, Francesco Corsello, Frank Diebold, Marie McGraw, Tony Liu, Glenn Rudebusch, Dalibor Stevanovic, David Wigglesworth, Boyuan Zhang, and members of the Penn Climate Econometrics Group. Moreover, we are thankful to three anonymous referees whose comments and suggestions greatly ameliorated this paper.

Data availability statement. The data are available from public sources that are cataloged in Table B1. The codes are available upon request.

\section{APPENDIX A}

\section{Bayesian Estimation Details}

Bayesian inference implies the use of priors, whose degree of informativeness is usually determined by the user. To be as agnostic as possible, we use the technique of Giannone et al. (2015) to choose the tightness of priors as to optimally balance bias and variance in a data-driven way. ${ }^{\mathrm{A} 1}$ The prior structure, however, must be chosen.

\footnotetext{
${ }^{\text {A1 }}$ Setting priors' tightness in such a way can be understood as analogous (at a philosophical level) to setting tuning parameters using cross-validation in machine learning.
}

We estimate our benchmark Bayesian VARCTIC with a standard Minnesota prior. In this simple framework $\boldsymbol{\Sigma}$, the variancecovariance matrix of the VAR residuals is treated as known. ${ }^{\mathrm{A} 2}$ Thus, the remaining parameters of the model reduce to the vectorized matrix $\boldsymbol{\beta}=\operatorname{vec}\left(\left[\boldsymbol{\Phi}_{1} \ldots \boldsymbol{\Phi}_{p} \mathbf{c}\right]^{\mathrm{T}}\right)$ of dimension $\left(M^{2} p+M\right) \times 1$. The posterior distribution of $\boldsymbol{\beta}, \pi(\beta \mid y)$, is obtained by the product of the likelihood function of the data $f(y \mid \boldsymbol{\beta})$ and the prior distribution of $\boldsymbol{\beta}, \pi(\boldsymbol{\beta})$. Hence, by sampling from the posterior distribution $\pi(\boldsymbol{\beta} \mid y) \propto f(y \mid \boldsymbol{\beta}) \pi(\boldsymbol{\beta})$, we can quantify both the uncertainty around $\boldsymbol{\beta}$, but also more interesting transformations of it, such as IRFs and forecasts. ${ }^{\mathrm{A} 3}$ The prior distribution for $\boldsymbol{\beta}$ is the multivariate normal distribution $\pi(\boldsymbol{\beta}) \sim N\left(\boldsymbol{\beta}_{0}, \boldsymbol{\Sigma}_{0}\right)$. The Minnesota prior is a specific structure for values of both $\boldsymbol{\beta}_{0}$ and $\boldsymbol{\Sigma}_{0} .{ }^{A 4}$ In words, it allows concisely to parameterize heterogeneity in both the prior mean and variance. It consists of three major elements: the first one is about $\boldsymbol{\beta}_{0}$ and the last two concern $\boldsymbol{\Sigma}_{0}$.

1) For any equation $y_{m, t}$ with $m=1, \ldots, M$-where $M$ is the total number of observed variables in the VAR-all parameters are shrunk to 0 except for its first own lag $y_{m, t-1}$. The latter is usually shrunk to a value $b_{\mathrm{AR}}$ between 0.5 and 1. This can be interpreted as shrinking each VAR equation to the much simpler and parsimonious $\operatorname{AR}(1)$ process. Given the persistent nature of time series data, this structure for $\boldsymbol{\beta}_{0}$ is much more appropriate than that of ridge

\footnotetext{
${ }^{A} 2$ This choice is motivated by the fact that it facilitates the optimization of hyperparameters. As it turns out, optimizing tuning parameters has more impact on resulting IRFs and their respective credible regions than treating $\boldsymbol{\Sigma}$ as unknown, when using, for instance, an independent normal Wishart (with Gibbs sampling).

${ }^{\mathrm{A} 3}$ In the latter case, the credible region will naturally comprehend the uncertainty from the act of recursive forecasting itself, but also the fact that it relies on unknown parameters that must be estimated.

${ }^{\mathrm{A} 4} \mathrm{As}$ a reference, a ridge regression would imply $\boldsymbol{\beta}_{0}=0$ and $\boldsymbol{\Sigma}_{0}$ being a diagonal matrix with identical diagonal elements.
} 
TABLE 1. List of variables.

\begin{tabular}{|c|c|c|c|}
\hline Abbreviation & Description & Data source & URL \\
\hline Age & Gridded monthly mean of sea ice age & EASE-Grid sea ice age, version 4 & https://nsidc.org/data/nsidc-0611/versions/4 \\
\hline AT & $\begin{array}{l}\text { Gridded monthly mean of air } \\
\text { temperature }\end{array}$ & $\begin{array}{l}\text { NCEP-NCAR Reanalysis } 1: \\
\text { Surface }\end{array}$ & $\begin{array}{l}\text { https://www.esrl.noaa.gov/psd/data/gridded/data. } \\
\text { ncep.reanalysis.surface.html }\end{array}$ \\
\hline Albedo & $\begin{array}{l}\text { Gridded monthly mean of surface } \\
\text { albedo }\end{array}$ & MERRA-2 & $\begin{array}{l}\text { https://disc.gsfc.nasa.gov/datasets/M2TUNXRAD_ } \\
\text { 5.12.4/summary?keywords= merra- } 2\end{array}$ \\
\hline $\mathrm{CO}_{2}$ & Global monthly mean of $\mathrm{CO}_{2}$ & $\begin{array}{l}\text { NOAA-Earth System } \\
\text { Research Laboratories }\end{array}$ & $\begin{array}{l}\text { https://www.esrl.noaa.gov/gmd/ccgg/trends/gl_ } \\
\text { data.html }\end{array}$ \\
\hline LWGAB & $\begin{array}{l}\text { Gridded monthly mean of surface } \\
\text { absorbed longwave radiation }\end{array}$ & MERRA-2 & $\begin{array}{l}\text { https://disc.gsfc.nasa.gov/datasets/M2TUNXRAD_ } \\
\text { 5.12.4/summary?keywords=merra- } 2\end{array}$ \\
\hline LWGEM & $\begin{array}{l}\text { Gridded monthly mean of } \\
\text { longwave flux emitted from } \\
\text { surface }\end{array}$ & MERRA-2 & $\begin{array}{l}\text { https://disc.gsfc.nasa.gov/datasets/M2TUNXRAD_ } \\
\text { 5.12.4/summary?keywords = merra- } 2\end{array}$ \\
\hline LWGNT & $\begin{array}{l}\text { Gridded monthly mean of surface } \\
\text { net downward longwave flux }\end{array}$ & MERRA-2 & $\begin{array}{l}\text { https://disc.gsfc.nasa.gov/datasets/M2TUNXRAD } \\
5.12 .4 / \text { summary?keywords }=\text { merra- } 2\end{array}$ \\
\hline LWTUP & $\begin{array}{l}\text { Gridded monthly mean of } \\
\text { upwelling longwave flux at TOA }\end{array}$ & MERRA-2 & $\begin{array}{l}\text { https://disc.gsfc.nasa.gov/datasets/M2TUNXRAD_ } \\
\text { 5.12.4/summary?keywords = merra- } 2\end{array}$ \\
\hline PR & $\begin{array}{l}\text { Gridded monthly mean of } \\
\text { precipitation }\end{array}$ & $\begin{array}{l}\text { CPC Merged Analysis of } \\
\text { Precipitation (CMAP) }\end{array}$ & $\begin{array}{l}\text { https://www.esrl.noaa.gov/psd/data/gridded/data. } \\
\text { cmap.html }\end{array}$ \\
\hline SST & $\begin{array}{l}\text { Median Northern Hemisphere } \\
\text { mean sea surface temperature } \\
\text { anomaly (relative to 1961-90) }\end{array}$ & Met Office Hadley Centre & $\begin{array}{l}\text { https://www.metoffice.gov.uk/hadobs/hadsst3/data/ } \\
\text { download.html }\end{array}$ \\
\hline SIE & $\begin{array}{l}\text { Gridded monthly mean of sea ice } \\
\text { extent }\end{array}$ & Sea Ice Index, version 3 & https://nsidc.org/data/g02135 \\
\hline SWGNT & $\begin{array}{l}\text { Gridded monthly mean of surface } \\
\text { net downward shortwave flux }\end{array}$ & MERRA-2 & $\begin{array}{l}\text { https://disc.gsfc.nasa.gov/datasets/M2TUNXRAD_ } \\
\text { 5.12.4/summary?keywords = merra- } 2\end{array}$ \\
\hline SWTNT & $\begin{array}{l}\text { Gridded monthly mean of TOA } \\
\text { net downward shortwave flux }\end{array}$ & MERRA-2 & $\begin{array}{l}\text { https://disc.gsfc.nasa.gov/datasets/M2TUNXRAD_ } \\
\text { 5.12.4/summary?keywords = merra- } 2\end{array}$ \\
\hline TAUTOT & $\begin{array}{l}\text { Gridded monthly mean of in-cloud } \\
\text { optical SIT of all clouds }\end{array}$ & MERRA-2 & $\begin{array}{l}\text { https://disc.gsfc.nasa.gov/datasets/M2TUNXRAD_ } \\
\text { 5.12.4/summary?keywords= merra- } 2\end{array}$ \\
\hline SIT & $\begin{array}{l}\text { Gridded monthly mean of sea ice } \\
\text { thickness }\end{array}$ & PIOMAS & $\begin{array}{l}\text { http://psc.apl.uw.edu/research/projects/arctic-sea- } \\
\text { ice-volume-anomaly/data/model_grid }\end{array}$ \\
\hline $\mathrm{TCC}$ & $\begin{array}{l}\text { Gridded monthly mean of total } \\
\text { cloud cover }\end{array}$ & $\begin{array}{l}\text { NCEP-NCAR reanalysis } \\
\text { monthly means and other } \\
\text { derived variables }\end{array}$ & $\begin{array}{l}\text { https://www.esrl.noaa.gov/psd/data/gridded/data. } \\
\text { ncep.reanalysis.derived.otherflux.html }\end{array}$ \\
\hline $\mathrm{TS}$ & $\begin{array}{l}\text { Gridded monthly mean of surface } \\
\text { skin temperature }\end{array}$ & MERRA-2 & $\begin{array}{l}\text { https://disc.gsfc.nasa.gov/datasets/M2TUNXRAD_ } \\
\text { 5.12.4/summary?keywords= merra- } 2\end{array}$ \\
\hline
\end{tabular}

regression (or LASSO), which shrinks all coefficients homogeneously toward 0 .

2) It is often observed in multivariate time series models that $y_{m, t-1} \rightarrow y_{m, t}$ will be significantly stronger than almost any of the $y_{\tilde{m}, t-1} \rightarrow y_{m, t}$ (with $\tilde{m} \neq m$ ) relationships. Therefore $\lambda_{2}$ calibrates the relative intensity of shrinking dynamic cross-correlations versus that of autocorrelations.

\footnotetext{
${ }^{\text {A5 }}$ For further details, explicit mathematical formulation of the prior, and additional discussion on priors for VARs, the reader is referred to Dieppe et al. (2016).
}

3) Distant partial lag relationships (say, $y_{m, t-12} \rightarrow y_{m, t}$ ) are expected to be of smaller magnitude than close ones like $y_{m, t-1} \rightarrow y_{m, t}$, and $y_{m, t-2} \rightarrow y_{m, t}$. The additional intensity of distant lags shrinkage is determined by $\lambda_{3}$.

The overall tightness of the prior apparatus is determined by $\lambda_{1}$. ${ }^{\mathrm{A} 5}$ To draw a parallel to penalized regression (like ridge and LASSO), a small $\lambda_{1}$ in a Bayesian VAR (BVAR) increases regularization in a way analogous to increasing the $\lambda_{\text {RIDGE }}$-that is, by pushing the BVAR estimate $\hat{\Phi}$ away from $\hat{\Phi}_{\text {OLs }}$. Following Giannone et al. (2015), we optimize/estimate hyperparameters within some grid and the total number of posterior draws is 2000. The optimal values for VARCTIC 8 are $\left\{b_{\mathrm{AR}}, \lambda_{1}, \lambda_{2}, \lambda_{3}\right\}=\{0.9,0.3,0.5,1.5\}$. We fix the number of 

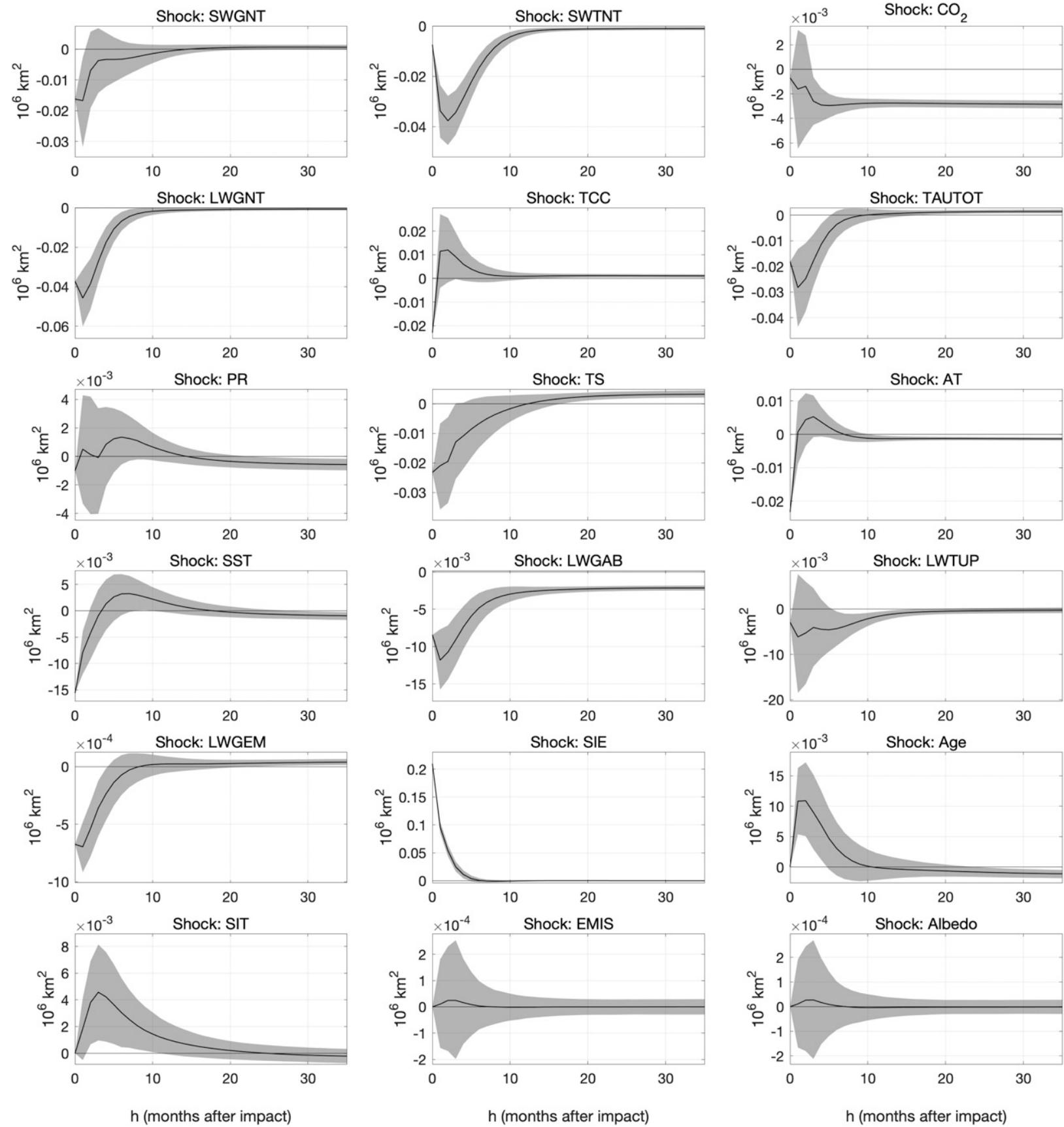

FIG. A1. IRFs: Response of sea ice extent in VARCTIC 18. Shading indicates the $90 \%$ credible region.

lags in VARCTIC 8 to $P=12$ and to $P=3$ in VARCTIC 18 , respectively.

Finally, given the very smooth look of deseasonalized $\mathrm{CO}_{2}$ in Fig. 1, one could worry that it merely acts as a proxy for an omitted linear trend. We view the use of trends as undesirable in our multivariate setup as it would undermine the capacity of the VARCTIC to be a "complete" model. Including a trend would make it rely on an unknown/unexplained latent force, which is at odds with the main goal of our modeling strategy. For the sake of completeness, we nevertheless estimate such models to find out that the inclusion of an exogenous time trend is in fact not preferred by the data according to the deviance information criterion [DIC, a generalization of the well-known Akaike information criterion (AIC)]. VARCTIC 8 has a DIC of -6894.35 and adding an exogenous trend makes it -6817.32 . The smallest value being preferred, this justifies on a data-driven basis the exclusion of the trend. While a seemingly technical point, this means that the VARCTIC 8 system, based solely on dynamic relationships of observable data, can generate/simulate the observed SIE downward path. 


\section{APPENDIX B}

\section{Results of VARCTIC 18}

VARCTIC 18, including all of the variables in Table B1, tests the robustness of VARCTIC 8 projection of SIE. The ordering of variables in VARCTIC 18 reads as follows: SWGNT, SWTNT, $\mathrm{CO}_{2}$, LWGNT, TCC, TAUTOT, PR, TS, AT, SST, LWGAB, LWTUP, LWGEM, SIE, age, SIT, EMIS, and albedo. Due to the increased number of variables, the lags were reduced to 3 and the estimation period starts in 1984 due to some series not being available any earlier. With more parameters to estimate, the prior specification slightly tightens to $\left\{b_{\mathrm{AR}}, \lambda_{1}, \lambda_{2}, \lambda_{3}\right\}=\{0.8,0.5,0.5,3\}$.

The forecasts of SIE under the specification of VARCTIC 18 are all reported in Fig. B1. This includes both the unconditional forecast and those conditional on RCPs. The median unconditional VARCTIC 18 forecast a blue Arctic in September 2062 , which is in the very neighborhood of VARCTIC 8. This result suggests that VARCTIC 8 comprises the key variables for a proper and robust long-run projection of Arctic sea ice. The projected ice-free dates under the RCP6 and RCP8.5 scenarios are also consistent with the results reported by VARCTIC 8 in Fig. 5a. The trajectory of SIE under RCP2.6, however, slightly changes and seems to stabilize rather than recover by the end of the century.

The IRFs of SIE are shown in Fig. B1. Those of key variables (as included in VARCTIC 18) remain roughly unchanged in VARCTIC 18. Most interestingly, in VARCTIC 18, not only $\mathrm{CO}_{2}$ shock has the effect of triggering a durably decreasing SIE, but also LWGAB, which measures the longwave radiation absorbed by the surface and AT. Many other shocks have significant impacts in the short run but only $\mathrm{CO}_{2}$, LWGAB, and AT shocks have the unique property of durably pushing the system out of the former equilibrium.

\section{REFERENCES}

Amstrup, S., E. DeWeaver, D. Douglas, B. Marcot, G. Durner, C. Bitz, and D. Bailey, 2010: Greenhouse gas mitigation can reduce sea-ice loss and increase polar bear persistence. Nature, 468, 955-958, https://doi.org/10.1038/nature09653.

Auerbach, A. J., and Y. Gorodnichenko, 2012: Measuring the output responses to fiscal policy. Amer. Econ. J. Econ. Policy, 4 (2), 1-27, https://doi.org/10.1257/pol.4.2.1.

Bachmann, R., and E. R. Sims, 2012: Confidence and the transmission of government spending shocks. J. Monet. Econ., 59, 235-249, https://doi.org/10.1016/j.jmoneco.2012.02.005.

Banbura, M., D. Giannone, and L. Reichlin, 2010: Large Bayesian vector auto regressions. J. Appl. Econ., 25, 71-92, https:// doi.org/10.1002/jae.1137.

Bernanke, B. S., M. Gertler, M. Watson, C. A. Sims, and B. M. Friedman, 1997: Systematic monetary policy and the effects of oil price shocks. Brookings Pap. Econ. Act., 1997, 91-157, https://doi.org/10.2307/2534702.

_ - J. Boivin, and P. Eliasz, 2005: Measuring the effects of monetary policy: A factor-augmented vector autoregressive (FAVAR) approach. Quart. J. Econ., 120, 387-422, https:// doi.org/10.1162/0033553053327452.

Bhatt, U., and Coauthors, 2019: Sea ice outlook: 2019 August report. https://www.arcus.org/sipn/sea-ice-outlook/2019/august.
Bitz, C., and G. Roe, 2004: A mechanism for the high rate of sea ice thinning in the Arctic Ocean. J. Climate, 17, 36233632, https://doi.org/10.1175/1520-0442(2004)017<3623: AMFTHR $>2.0 . \mathrm{CO} ; 2$.

Björk, G., C. Stranne, and K. Borenäs, 2013: The sensitivity of the Arctic Ocean sea ice thickness and its dependence on the surface albedo parameterization. J. Climate, 26, 1355-1370, https://doi.org/10.1175/JCLI-D-12-00085.1.

Burt, M., D. Randall, and M. Branson, 2016: Dark warming. J. Climate, 29, 705-719, https://doi.org/10.1175/JCLI-D-15-0147.1.

Carslaw, K., R. Harrison, and J. Kirkby, 2002: Cosmic rays, clouds, and climate. Science, 298, 1732-1737, https://doi.org/10.1126/ science.1076964.

Chavas, J.-P., and C. Grainger, 2019: On the dynamic instability of Arctic sea ice. npj Climate Atmos. Sci., 2, 23, https://doi.org/ 10.1038/s41612-019-0080-x.

Choi, I., 2015: Almost All about Unit Roots: Foundations, Developments, and Applications. Cambridge University Press, 279 pp.

Christiano, L. J., M. Eichenbaum, and C. L. Evans, 1999: Monetary policy shocks: What have we learned and to what end? Handbook Macroeconomics, 1, 65-148, https://doi.org/10.1016/ S1574-0048(99)01005-8.

Dai, A., D. Luo, M. Song, and J. Liu, 2019: Arctic amplification is caused by sea-ice loss under increasing $\mathrm{CO}_{2}$. Nat. Commun., 10, 121, https://doi.org/10.1038/s41467-018-07954-9.

Diebold, F. X., and G. Rudebusch, 2021: Probability assessments of an ice-free Arctic: Comparing statistical and climate model projections. J. Econometrics, https://doi.org/10.1016/j.jeconom. 2020.12.007, in press.

Dieppe, A., R. Legrand, and B. van Roye, 2016: The BEAR toolbox. Working Paper Series, No. 1934, European Central Bank, 290 pp., https://www.ecb.europa.eu/pub/pdf/scpwps/ecbwp1934.en.pdf.

Elliott, G., 1998: On the robustness of cointegration methods when regressors almost have unit roots. Econometrica, 66, 149-158, https://doi.org/10.2307/2998544.

Fanchon, P., and J. Wendel, 1992: Estimating VAR models under non-stationarity and cointegration: Alternative approaches for forecasting cattle prices. Appl. Econ., 24, 207-217, https:// doi.org/10.1080/00036849200000119.

Gelaro, R., and Coauthors, 2017: The Modern-Era Retrospective Analysis for Research and Applications, version 2 (MERRA-2). J. Climate, 30, 5419-5454, https://doi.org/10.1175/JCLI-D-16-0758.1.

Giannone, D., M. Lenza, and G. E. Primiceri, 2015: Prior selection for vector autoregressions. Rev. Econ. Stat., 97, 436-451, https://doi.org/10.1162/REST_a_00483.

,-- , and -2019 : Priors for the long run. J. Amer. Stat. Assoc., 114, 565-580, https://doi.org/10.1080/01621459.2018. 1483826.

Goosse, H., and Coauthors, 2018: Sea ice outlook: 2019 August report. Nat. Commun., 9, 1919, https://doi.org/10.1038/s41467-018-04173-0.

Goulet Coulombe, P., 2020: The macroeconomy as a random forest. 76 pp., https://arxiv.org/abs/2006.12724.

Granger, C. W., 1969: Investigating causal relations by econometric models and cross-spectral methods. Econometrica, 37, 424438, https://doi.org/10.2307/1912791.

Graversen, R. G., T. Mauritsen, S. Drijfhout, M. Tjernström, and S. Mårtensson, 2011: Warm winds from the Pacific caused extensive Arctic sea-ice melt in summer 2007. Climate Dyn., 36, 2103-2112, https://doi.org/10.1007/s00382-010-0809-z.

Horvath, S., J. Stroeve, B. Rajagopalan, and W. Kleiber, 2020: A Bayesian logistic regression for probabilistic forecasts of the minimum September Arctic sea ice cover. Earth Space Sci., 7, e2020EA001176, https://doi.org/10.1029/2020EA001176. 
Hyndman, R. J., 2010: Forecasting with long seasonal periods. Hyndsight blog, 29 September 2010, https://robjhyndman.com/ hyndsight/longseasonality/.

Jahn, A., J. Kay, M. Holland, and D. Hall, 2016: How predictable is the timing of a summer ice-free Arctic? Geophys. Res. Lett., 43, 9113-9120, https://doi.org/10.1002/2016GL070067.

Kay, J., and Coauthors, 2015: The Community Earth System Model (CESM) large ensemble project: A community resource for studying climate change in the presence of internal climate variability. Bull. Amer. Meteor. Soc., 96, 1333-1349, https:// doi.org/10.1175/BAMS-D-13-00255.1.

Kilian, L., and H. Lütkepohl, 2017: Structural Vector Autoregressive Analysis. Cambridge University Press, 734 pp.

Kwok, R., 2018: Arctic sea ice thickness, volume, and multiyear ice coverage: Losses and coupled variability (1958-2018). Environ. Res. Lett., 13, 105005, https://doi.org/10.1088/1748-9326/aae3ec.

Liang, S. X., 2014: Unraveling the cause-effect relation between time series. Phys. Rev. E, 90, 052150, https://doi.org/10.1103/ PhysRevE.90.052150.

Litterman, R. B., 1986: Forecasting with Bayesian vector autoregressions-Five years of experience. J. Bus. Econ. Stat., 4, 25-38, https://doi.org/10.1080/07350015.1986.10509491.

McGraw, M. C., and E. A. Barnes, 2018: Memory matters: A case for Granger causality in climate variability studies. J. Climate, 31, 3289-3300, https://doi.org/10.1175/JCLI-D-17-0334.1.

$\longrightarrow$, and —, 2020: New insights on subseasonal Arctic-midlatitude causal connections from a regularized regression model. J. Climate, 33, 213-228, https://doi.org/10.1175/JCLI-D-19-0142.1.

Meier, W., and Coauthors, 2014: Arctic sea ice in transformation: A review of recent observed changes and impacts on biology and human activity. Rev. Geophys., 52, 185-217, https://doi.org/ 10.1002/2013RG000431.

Melillo, J., T. Richmond, and G. Yohe, 2014: Northeast region. Climate Change Impacts in the United States: The Third National Climate Assessment, U.S. Global Change Research Program, 371-395, https://doi.org/10.7930/J0SF2T3P.

Notz, D., 2017: Arctic sea ice seasonal-to-decadal variability and long-term change. PAGES Mag., 25, 14-19, https://doi.org/ 10.22498/pages.25.1.14.

_ , and J. Marotzke, 2012: Observations reveal external driver for Arctic sea-ice retreat. Geophys. Res. Lett., 39, L08502, https://doi.org/10.1029/2012GL051094.

, and J. Stroeve, 2016: Observed Arctic sea-ice loss directly follows anthropogenic $\mathrm{CO}_{2}$ emission. Science, 354, 747-750, https://doi.org/10.1126/science.aag2345.

_- , and Coauthors, 2020: Arctic sea ice in CMIP6. Geophys. Res. Lett., 47, e2019GL086749, https://doi.org/10.1029/ 2019GL086749.

Oelke, C., T. Zhang, M. Serreze, and R. Armstrong, 2003: Regional-scale modeling of soil freeze/thaw over the Arctic drainage basin. J. Geophys. Res., 108, 4314, https://doi.org/ 10.1029/2002JD002722.

Park, H.-S., S. Lee, Y. Kosaka, S.-W. Son, and S.-W. Kim, 2015: The impact of Arctic winter infrared radiation on early summer sea ice. J. Climate, 28, 6281-6296, https://doi.org/10.1175/JCLI-D-14-00773.1.

Parkinson, C., and J. Comiso, 2013: On the 2012 record low Arctic sea ice cover: Combined impact of preconditioning and an August storm. Geophys. Res. Lett., 40, 1356-1361, https:// doi.org/10.1002/grl.50349.

Perovich, D., and C. Polashenski, 2012: Albedo evolution of seasonal Arctic sea ice. Geophys. Res. Lett., 39, L08501, https:// doi.org/10.1029/2012GL051432.
Pesaran, M. H., T. Schuermann, and L. V. Smith, 2009: Forecasting economic and financial variables with global VARs. Int. J. Forecast., 25, 642-675, https://doi.org/10.1016/j.ijforecast. 2009.08.007.

Polvani, L., M. Previdi, M. England, G. Chiodo, and K. Smith, 2020: Substantial twentieth-century Arctic warming caused by ozone-depleting substances. Nat. Climate Change, 10, 130133, https://doi.org/10.1038/s41558-019-0677-4.

Screen, J. A., and I. Simmonds, 2010: The central role of diminishing sea ice in recent Arctic temperature amplification. Nature, 464, 1334-1337, https://doi.org/10.1038/nature09051.

_ , and C. Deser, 2019: Pacific Ocean variability influences the time of emergence of a seasonally ice-free Arctic Ocean. Geophys. Res. Lett., 46, 2222-2231, https://doi.org/10.1029/ 2018GL081393.

,-- , and L. Sun, 2015: Projected changes in regional climate extremes arising from Arctic sea ice loss. Environ. Res. Lett., 10, 084006, https://doi.org/10.1088/1748-9326/10/8/084006.

Serreze, M. C., and J. Stroeve, 2015: Arctic sea ice trends, variability and implications for seasonal ice forecasting. Philos. Trans. Roy. Soc., 373A, 20140159, https://doi.org/10.1098/ rsta.2014.0159.

Sigmond, M., J. Fyfe, and N. Swart, 2018: Ice-free Arctic projections under the Paris Agreement. Nat. Climate Change, 8, 404408, https://doi.org/10.1038/s41558-018-0124-y.

Sims, C. A., 1980: Macroeconomics and reality. Econometrica, 48 (1), 1-48, https://doi.org/10.2307/1912017.

— , and T. Zha, 2006: Does monetary policy generate recessions? Macroecon. Dyn., 10, 231-272, https://doi.org/10.1017/ S136510050605019X.

Stock, J. H., and M. W. Watson, 2005: Implications of dynamic factor models for VAR analysis. Tech. Rep., National Bureau of Economic Research, 66 pp.

Stroeve, J., and D. Notz, 2018: Changing state of Arctic sea ice across all seasons. Environ. Res. Lett., 13, 103001, https:// doi.org/10.1088/1748-9326/aade56.

_, V. Kattsov, A. Barrett, M. Serreze, T. Pavlova, M. Holland, and W. Meier, 2012: Trends in Arctic sea ice extent from CMIP5, CMIP3 and observations. Geophys. Res. Lett., 39, L16502, https://doi.org/10.1029/2012GL052676.

Stuecker, M., and Coauthors, 2018: Polar amplification dominated by local forcing and feedbacks. Nat. Climate Change, 8, 10761081, https://doi.org/10.1038/s41558-018-0339-y.

Taylor, K., R. Stouffer, and G. Meehl, 2012: An overview of CMIP5 and the experiment design. Bull. Amer. Meteor. Soc., 93, 485498, https://doi.org/10.1175/BAMS-D-11-00094.1.

Waggoner, D., and T. Zha, 1999: Conditional forecasts in dynamic multivariate models. Rev. Econ. Stat., 81, 639-651, https:// doi.org/10.1162/003465399558508.

Wang, L., X. Yuan, M. Ting, and C. Li, 2016: Predicting summer Arctic sea ice concentration intraseasonal variability using a vector autoregressive model. J. Climate, 29, 1529-1543, https:// doi.org/10.1175/JCLI-D-15-0313.1.

Wang, M., and J. E. Overland, 2009: A sea ice free summer Arctic within 30 years? Geophys. Res. Lett., 36, L07502, https:// doi.org/10.1029/2009GL037820.

_ and - 2012: A sea ice free summer Arctic within 30 years: An update from CMIP5 models. Geophys. Res. Lett., 39, L18501, https://doi.org/10.1029/2012GL052868.

Winton, M., 2013: Sea Ice-Albedo Feedback and Nonlinear Arctic Climate Change, Geophys. Monogr., Vol. 180, Amer. Geophys. Union, 111-131. 